\title{
Study on the Bending Capacity of Cold-formed Stainless Steel Hollow Sections
}

\section{ZHENG Baofeng}

PhD Candidate, School of Civil Engineering, Key Lab of Concrete and Prestressed Concrete Structures of Ministry of Education, Southeast University, NO.2 Sipailou Nanjing, China. Corresponding author, Tel.: +86 02583792950; E-mail address: zhengbaofengseu@ gmail.com

\section{SHU Ganping}

Professor, School of Civil Engineering, Key Lab of Concrete and Prestressed Concrete Structures of Ministry of Education, Southeast University, NO.2 Sipailou Nanjing, China. E-mail address: shuganping@seu.edu.cn

\section{XIN Lianchun}

Engineer, Architects \& Engineers, LTD of Southeast University, Nanjing, China.

YANG Ran

Engineer, Anhui Huadian Engineering Consultation \& Design CO. LTD., Hefei, China.

\section{JIANG Qinglin}

Manager, Jiangsu Dongge Stainless Steel Ware Co., Ltd.

\begin{abstract}
Experimental and numerical studies on the bending capacity of cold-formed stainless steel rectangular and circular hollow sections are reported. Eight four-point bending tests were carried out. Material properties, geometric imperfections, bending capacities, moment-curvature curves were obtained in the tests. Finite element models were developed, and were verified using the test data. Material nonlinearity and geometric imperfections were considered in the modeling. Parameter studies were conducted to expand test data with different material properties and section slenderness. Based on the test results and the finite element analysis results, direct strength formulas were proposed for rectangular and circular hollow sections, respectively. Test data were collected from literatures as references, and compared with predictions of the Eurocode, the American code, the Australian/New Zealand code, the Chinese code, and the continuous strength method (CSM). Comparisons show that the Eurocode, the American code, the Australian/New Zealand code, and the Chinese code are generally conservative. The Chinese code provides most conservative predictions, due to the neglect of strain hardening effect and section plasticity, especially for stocky cross sections. The performance of CSM method is better than the design codes. The proposed formulas show better accuracy in predicting bending capacities of cold-formed stainless steel hollow sections.
\end{abstract}

Keywords: Cold-formed, Stainless steel, Hollow sections, Bending capacity, tests, Direct strength method 


\section{Abstract}

Experimental and numerical studies on the bending capacity of cold-formed stainless steel rectangular and circular hollow sections are reported. Eight four-point bending tests were carried out. Material properties, geometric imperfections, bending capacities, moment-curvature curves were obtained in the tests. Finite element models were developed, and were verified using the test data. Material nonlinearity and geometric imperfections were considered in the modeling. Parameter studies were conducted to expand test data with different material properties and section slenderness Based on the test results and the finite element analysis results, direct strength formulas were proposed for rectangular and circular hollow sections, respectively. Test data were collected from literatures as references, and compared with predictions of the Eurocode, the American code, the Australian/New Zealand code, the Chinese code, and the continuous strength method (CSM). Comparisons show that the Eurocode, the American code, the Australian/New Zealand code, and the Chinese code are generally conservative. The Chinese code provides most conservative predictions, due to the neglect of strain hardening effect and section plasticity, especially for stocky cross sections. The performance of CSM method is better than the design codes. The proposed formulas show better accuracy in predicting bending capacities of cold-formed stainless steel hollow sections.

Keywords: Cold-formed, Stainless steel, Hollow sections, Bending capacity, tests, Direct strength method 


\section{Introduction}

Stainless steel has become an attractive material in building constructions due to its durability, favorable mechanical properties, and esthetic appearance. Researches have been carried out on the behaviors of stainless steel members, and design codes have been issued in some countries. Nevertheless, stainless steel contains chromium and nickel, which are more expensive than ferrum in the carbon steel. The high initial cost of the material is the most important issue that restraints its wide application. Using the cross-section with excellent structural behaviors, and improving the accuracy of predictions of design codes are critical points to be considered. In this paper, study was focused on the bending behaviors of cold-formed stainless steel hollow sections.

Johnson and Winter [1] carried out tests on cold-formed stainless steel hat sections and box sections to study the effectiveness of compression flanges and webs. Rasmussen and Hancock [2], Talja and Salmi [3], Real and Mirambell [4], Gardner et al. [5][6], Zhou and Young [7], Theodanous and Gardner [8], Zheng et al. [9], Huang and Young [10], Afshan and Gardner [11], Bock et al.[12], Theofanous et al. [13], Zhao et al. [14][15][16] conducted tests on cold-formed stainless steel rectangular hollow sections in bending. Compared to the number of tests on the rectangular hollow sections, few tests were founded in literature on the circular hollow sections. Rasmussen and Hancock [2], Kiymaz[17], Way[18] performed tests on cold-formed stainless steel circular hollow sections in bending. In these experiments, several grades of stainless steel were considered, including austenitic stainless steel 1.4301(304), 1.4307(304L), 1.4318(301L), 1.4401(316), 1.4404(316L), 1.4435(316L), 1.4541(321), 1.4571(316Ti), ferritic stainless steel 1.4003(3Cr12), 1.4509(441), duplex stainless steel 1.4462(2205), and lean duplex stainless steel 1.4162(32101). 
Apart from the experimental studies, design methods were proposed for the predictions of bending capacity of stainless steel hollow sections. The Eurocode 3[19] employs the concept of cross-section classification in the treatment of local buckling, and allows to use section plasticity for stocky cross sections. In the American code[20], section plasticity can be used in the design of rectangular hollow sections, but it is not applicable to the design of circular hollow sections. The provisions in the Australian/New Zealand code[21] are very similar to those in American code, except that partial plasticity design is permitted for the circular hollow section bending members. In the Chinese code[22], plastic design is not allowed for cold formed stainless steel members, and the effective width method is adopted to account for the effectiveness of slender sections. Experimental studies show that these design code are conservative in predicting the bending capacity. To improve the performance of the design codes, Gardner's group [23-26] developed a new method to utilize the strain hardening property of stainless steel, named the continuous strength method (CSM). Huang and Young [10] modified the effective width method in the Eurocode 3[19], and the direct strength method (DSM) formula in the North American Cold-formed Steel Specification[27].

The objective of this paper is to investigate the prediction performance of the Chinese code[22] and to develop the direct strength method (DSM) for stainless steel hollow sections to utilize the strain hardening properties of stainless steel. A series of tests on cold-formed stainless steel hollow sections are firstly presented. Finite element models were developed and validated, and then used to perform parameter analysis. DSM formulas were proposed based on the finite element results. Test data in literatures were collected and compared with the predictions of design codes, the continuous strength method, and the direst strength method. 


\section{Experimental study}

Experimental investigations consist of material tests on cold-formed tubes and the virgin plate, four four-point bending tests on rectangular hollow sections, and four four-point bending tests on circular hollow sections. All the test specimens were cold-rolled from stainless steel plate of austenitic steel S30408 (1.4301)[28]. The steel plate was initially rolled into a circular hollow section and then crushed into a rectangular hollow section. The nominal cross-sections of the rectangular hollow sections are $70 \mathrm{~mm} \times 3 \mathrm{~mm}$ and $100 \mathrm{~mm} \times 3 \mathrm{~mm}$. The nominal cross-sections of the circular hollow sections are $89 \mathrm{~mm} \times 3 \mathrm{~mm}$ and $127 \mathrm{~mm} \times 3 \mathrm{~mm}$.

\subsection{Material tests}

A series of material coupon tensile tests were carried out. To obtain the full information of the material properties around the cross section, the cross sections were cut into several strips. The positions of the strips are shown in Fig. 1. The width and the length of the strips are $10 \mathrm{~mm}$ and $150 \mathrm{~mm}$, respectively.

Sixteen coupons from the flat part and two coupons from the corner part were tested for the SHS $70 \mathrm{~mm} \times 3 \mathrm{~mm}$, respectively. For SHS $100 \mathrm{~mm} \times 3 \mathrm{~mm}$, twenty coupons were tested for the flat part, and two coupons were tested for the corner part. Six coupons were tested for each circular hollow section. Besides the coupons from the finished tubes, three coupons were cut from the virgin plate.

Coupon tensile tests were performed in a $100 \mathrm{kN}$ SANS universal testing machine. The tests were 
conducted in accordance with the Chinese standard GB/T 228.1-2010[29].The gauge length of the coupons was $50 \mathrm{~mm}$. Load rate was about $0.5 \mathrm{~mm} / \mathrm{min}$ before the strain reached 0.01 , and $5 \mathrm{~mm} / \mathrm{min}$ after that. Prior to testing, a pair of strain gauges were pasted on each face of the coupon to obtain the strain-stress curve. To get rid of introducing moment to the corner coupons, a pair of corner coupons were gripped symmetrically around the steel bar which was located at the end with the same radius as the internal radius of corner in the test specimens. Typical corner coupon is shown in Fig. 2.

Material test results were processed according to the strain-stress model proposed by Gardner[5]. The results of the material test are shown in Table 1 and Table 2 for virgin plates and the tubes, respectively. In these two tables, $E_{0}$ is the material Young's modulus, $\sigma_{0.2}$ is the material $0.2 \%$ proof stress, $n$ is a strain hardening exponent, $\sigma_{1.0}$ is the material $1.0 \%$ proof stress, $n_{0.2,1.0}$ is a strain hardening coefficient representing a curve that passes through 0.2 and $1.0, \sigma_{\mathrm{u}}$ is the ultimate tensile stress, $\delta$ is the percentage elongation after fracture.

From Table 1 and Table 2, it is concluded that: (1) the nominal yield strength $\sigma_{0.2}$ in the hollow sections are much higher than $\sigma_{0.2}$ of the virgin plates due to the cold working in the production process. The $\sigma_{0.2}(489.03 \mathrm{MPa})$ in the SHS70 $\times 3$ is over two times of that in the virgin material (243.26 MPa); (2) the ultimate strength is also increased due to cold working, but the degree of increase is not as higher as that of the nominal yield strength; (3) compared to the percentage elongation in the virgin plates, the percentage elongation in the hollow sections was lower. The percentage elongation in the corner part is still higher than $20 \%$, which shows very good ductility. 
(4) Because the coupons of virgin plates were curved when taken off from the coil, the elastic Young's modulus is a little bit lower than that of coupons of the hollow sections.

\subsection{Beam tests}

A total of eight specimens, (two specimens for each section), were tested under four-point bending condition. The dimensions of the specimens were measured, shown in Table 3 , using the nomenclatures defined in Fig. 1. Both the local and global geometric imperfections were measured. The global imperfections were measured using a Vernier caliper and one string. The tightened string was used to form a perfect straight line between the two ends, along the longitudinal direction of the specimen. The gap between the string and the edge of the specimen was measured using the Vernier caliper. The maximum value of the gap is regarded as the global imperfection. For the rectangular hollow sections, the local imperfections were examined using an arrangement comprising a dial gauge and a milling machine [5]. For the circular hollow sections, the local imperfections were measured using Vernier caliper. Local imperfections for the circular hollow sections are the average difference between the diameter at the weld and the diameter at the direction 90 degree to the weld.

All specimens with a total length of $1900 \mathrm{~mm}$ were simply supported between two steel rollers which allowed axial displacement of the beam's ends. The rollers were located $150 \mathrm{~mm}$ inward from the ends of the specimens and, resulting in a span of $1600 \mathrm{~mm}$. The specimens were loaded symmetrically at two points by using a spreader beam. The distance between the two loading point was $600 \mathrm{~mm}$. Two knife-hinge supports were settled between the spreader beam and the loading 
points to allow the rotation of the specimens during tests. Loads were applied by using a $300 \mathrm{kN}$ hand hydraulic bottle jack. To avoid the premature failure of the specimens at the loading points due to the concentrated loads, steel plates and steel rings were used to strengthen the cross-section at the loading points for rectangular and circular hollow specimens, respectively. The test configuration is shown in Fig. 3. The steel plate and the steel ring for strengthening are shown in Fig. 4.

A load cell was arranged at the top of the jack, below the bottom of the loading frame to record the total force applied on specimens. At each end of specimens, two displacement transducers (LVDT) were set on the top surface of specimens to measure the rotation of the ends. Another three displacement transducers were placed at the two loading points and the central point of the specimens to measure the vertical displacements. A data acquisition system was used to record the applied loads and the readings of displacement transducers.

Test results are listed in Table 4 . In this table, $F_{\mathrm{t}}$ is the maximum load applied using the hydraulic jack, $M_{\mathrm{t}}$ is the ultimate bending moment. For the slender sections, SHS100×3 and CHS127 $\times 3$, the major failure is the local buckling of the flange in compression. The compression flange buckles inwards with consistent deformation at the web. This type of failure mode is shown in Fig. 5(a) and (b) for rectangular and circular hollow sections, respectively. After reaching ultimate load, the stiffness of the specimen became negative, while the vertical displacement increased very fast. For the stocky sections, SHS70 3 and CHS $89 \times 3$, no cross-section buckling failure occurred during the tests. For SHS70 $\times 3$ specimens, at the last stage of the loading, the load reached a plateau, while the vertical displacement increased rapidly. For CHS $89 \times 3$ specimens, the circular cross-section 
between loading points became elliptical at the ultimate state, while the height of the cross section considerably decreased. Fig. 5(c) shows the failure mode of CHS89×3-1900a.

Fig. 6 shows the relationship between the moment at the central section and the curvature at the pure bending part. In this figure, the vertical axis is the moment at the center of the specimen, while the horizontal axis is the curvature of the specimen at the pure bending part. The curvatures were calculated using Eq. (1) [11]

$$
k=\frac{8\left(D_{\text {midspan }}-D_{\text {average }}\right)}{4\left(D_{\text {midspan }}-D_{\text {average }}\right)^{2}+L_{\text {midspan }}^{2}}
$$

where $D_{\text {midspan }}$ is the vertical deflection at mid span, $D_{\text {average }}$ is the average vertical displacement at the loading points, and $L_{\text {midspan }}$ is the length between the loading points.

\section{Finite element modeling and validation}

The finite element models of test specimens were developed in ABAQUS[30] using S9R5 element.

Two different models (Model 1 and Model 2) for every specimen were built. In Model 1, the full length of test specimens were built with pinned-roller constraint at the bearings shown in Fig. 7. To simulate the enhancement at the loading points and the actual constraint at the bearings, nodes of the cross-sections at the loading points and the supports were coupled with a set of reference points with rigid body constraint. Enhanced corner material properties were considered, and the enhanced region is assumed to extend as far as two times the thickness into the adjacent flat parts [5]. In Model 2, only the pure bending part of the test specimen was built. This model was simply-supported, and moments were applied at the two ends. Rigid body coupling was applied at the loading points. 
In these two models, the geometric imperfections were introduced into model by using the first eigen buckling mode scaled by the measured magnitude of local imperfection to the perfect structural model. For the cold formed sections, the major type of residual stresses is bending residual stress [31]. During tensile coupon tests, the coupons are straightened, which effectively reintroduces the bending residual stresses into the coupons. Therefore, provided the material properties are established using coupons cut from the cross-section, the effects of bending residual stresses are inherently present, and do not need to be defined explicitly in the numerical models[2][5][32].

Analysis results of these two models were compared with test results, shown in Table 5. In this table, $M_{\mathrm{t}}$ is the test bending strength, $M_{1 \mathrm{u}}$ and $M_{2 \mathrm{u}}$ are the predicted bending strength of Model 1 and Model 2 , respectively. It indicates that bending strength from the test is slightly (about $5 \%$ ) higher than that predicted by Model 1 on average. That is due to the friction between the knife-hinge and the steel plates (the steel rings for CHS) at the loading points. The test specimen was strengthened by the spreader beam due to the friction force. Although fine sand was used to reduce the friction, it was observed that the friction force pushed the knife-hinge together with the steel plates (the steel rings for CHS) moving towards the supports. Compared the last two columns in Table 5, it indicates that Model 1 and Model 2 provide the same predictions for the test specimens. These two models also provide similar eigen buckling modes, and failure modes. Considering the computation efforts, Model 2 is used in the following analyses.

Fig. 8 shows the failure modes predicted by the finite element results (Model 1). Compared with 
Fig. 5, it can be concluded that finite element model can predict failure modes correctly. Fig. 9 shows the moment-curvature curves obtained from tests and finite element models. Over all the moment-curvature curves predicted by finite element model agree well with the test curves. However, at the ultimate strength stage, the test curves are a little bit higher than the curves predicted by finite element models. That is mainly because of the friction force between the knife-hinge and the steel plates

\section{Proposed method}

\subsection{Parameter analysis}

The parameter analysis was based on the numerical simulation using Model 2. To expand the data on the bending capacity of cold-formed stainless steel hollow sections, bending members over a wider range of material properties and section slenderness were calculated. Thirty types of material parameters were used. The nominal yield strength considered includes $200 \mathrm{MPa}, 300 \mathrm{MPa}, 400 \mathrm{MPa}$, 500MPa, and 600MPa. The strain hardening exponent was set as 3, 4, 5, 6, 7, and 8. Two-stage material model proposed by Gardner [5] was used and material parameters for the second stage of the material model were predicted using approximate formulas [33]. These material properties could represent the commonly used austenitic and duplex stainless steel. Ferritic stainless steel, which has higher strain hardening exponent and lower $\sigma_{\mathrm{u}} / \sigma_{\mathrm{y}}$ ratio, was not covered in this paper. The consideration of enhanced corner material properties was simplified as specifying the average value of material properties in the flat and corner regions among the full cross section.

For the rectangular hollow sections, eighteen types of section slenderness were considered, ranging 
from 0.25 to 2.0 . It should be noted that the section slenderness is calculated using the local buckling stress of the whole cross section and the nominal yield stress. The definition of section slenderness is given in Eq. (2).

$$
\lambda=\sqrt{\frac{M_{y}}{M_{\mathrm{crl}}}}
$$

where $M_{\mathrm{y}}$ is the nominal yield moment and, $M_{\mathrm{crl}}$ is the eigen buckling moment of the whole cross section in bending. The overall profile of the cross-section is $100 \mathrm{~mm} \times 100 \mathrm{~mm}$ and the thickness varied according to the section slenderness. The outer corner radius is two times of the thickness.

For the circular hollow sections, twenty types of $D / t$ ratio were considered ranging from 10 to 300 , corresponding to the section slenderness from 0.1 to 1.5 . The outer diameter of the cross-section for all CHS sections is $200 \mathrm{~mm}$, and the thickness varied according to the section slenderness. The length of the members in the calculations was $1000 \mathrm{~mm}$ and $2000 \mathrm{~mm}$ for rectangular and circular hollow sections, respectively, which is long enough to minimize the influence of the rigid body coupling at the ends to the bending capacity.

Local imperfections were introduced into finite element models using the first eigen buckling mode scaled by the experienced imperfection magnitudes shown in Eq. (3) [5].

$$
w / t= \begin{cases}0.023\left(\sigma_{y} / \sigma_{c r}\right) & \text { for RHS } \\ 0.2 & \text { for CHS }\end{cases}
$$

where $w$ is the imperfection magnitude, $t$ is the thickness of cross section, $\sigma_{\mathrm{y}}$ is the nominal yield stress, and $\sigma_{\mathrm{cr}}$ is the elastic buckling stress. The residual stresses were not considered in the finite element model. 
Totally 540 models were analyzed for rectangular hollow sections, and 600 models were analyzed for circular hollow sections. Results of parameter analysis are shown in Figs. 10 and 11 (the black dots in these figures). It indicates that the bending capacity ratio $\left(M_{\mathrm{v}} / M_{\mathrm{y}}\right)$ is related to the section slenderness as well as material property. For the members with the same section slenderness, the maximum variation on the bending capacity ratio reaches up to $15 \%$ due to the difference of material properties. In order to propose simple and practical design formulas, the influence of material properties on the bearing capacity is neglected and the proposed formulas will be aimed to be applicable to the commonly used stainless steel grades

\subsection{DSM formulas}

Direct strength method (DSM) is one of the most popular design methods in predicting capacities of thin-walled members. DSM is initially developed to replace the effective width method, which is too complex in predicting the distortional buckling capacity. Recently, DSM has been utilized in the design of stainless steel structural members. In this paper, the DSM method was employed to develop a prediction formula for the local buckling capacity of stainless steel hollow sections.

DSM formulas were obtained by fitting the finite element results shown in Figs.10 and 11. Design formula for rectangular and circular hollow sections are shown in Eqs. (4) and (5), respectively.

$$
\begin{gathered}
M_{u}=\frac{1.1-0.17 \lambda^{1.82}}{\lambda^{0.32}} M_{y} \leq \sigma_{u} W_{p} \\
M_{u}=\frac{1-0.62 \lambda}{\lambda^{0.33}} M_{y} \leq \sigma_{u} W_{p}
\end{gathered}
$$

where $M_{\mathrm{u}}$ is the predicted bending capacity, $\lambda$ is the section slenderness, $M_{\mathrm{y}}$ is the yield moment, $\sigma_{\mathrm{u}}$ 
is the ultimate tensile strength, and $W_{\mathrm{p}}$ is the plastic section modulus. It should be noted that $\sigma_{\mathrm{u}} W_{\mathrm{p}}$ was set as the maximum of the designed bending capacity to avoid mathematic error for compact cross sections.

When using the DSM formulas, section slenderness $\lambda$ is an important factor. According to the definition of section slenderness (Eq. (2)), critical local buckling moment $M_{\mathrm{crl}}$ should be determined in advance. For rectangular hollow sections, critical local buckling moment $M_{\text {crl }}$ can be expressed by Eq. (6).

$$
M_{c r l}=k_{f} \frac{4 \pi^{2} E}{12\left(1-v^{2}\right)}\left(\frac{t}{b}\right)^{2} W
$$

where, $E$ is the elastic Young's modulus, $v$ is the Poisson ratio; $t$ is the thickness, $W$ is the elastic section modulus, $b$ is the width of the flange measured from the mid-thickness $(B-t)$, and $k_{\mathrm{f}}$ is the interactive factor, which indicates the contribution of the web stiffness to the local buckling of the flange.

In order to develop an expression for the interactive factor $k_{\mathrm{f}}$, sixteen rectangular hollow sections with different aspect ratio $B / H$ were analyzed using the finite strip software CUFSM [34][35]. In the CUFSM, a mode identification technique is utilized to obtain the pure local buckling mode. Typical calculation result is shown in Fig. 12.

Fig. 13 shows the analysis results along with the aspect ratio $B / H$. It indicates that as the ratio of $B / H$ increases, the interactive factor $k_{\mathrm{f}}$ increases as well. The interactive factor is more sensitive to the ratio of $B / H$ as the ratio of $B / H$ is less than 0.5. Based on the calculation results, the interactive 
factor $k_{\mathrm{f}}$ is expressed in a two-stage expression, i.e. Eq. (7).

$$
k_{f}= \begin{cases}3.29 \frac{B}{H}-0.37 & 0.1<\frac{B}{H}<0.5 \\ 0.27 \frac{B}{H}+1.14 & 1.0>\frac{B}{H} \geq 0.5\end{cases}
$$

where $B$ is the overall width of the flange, and $H$ is the overall height of the cross section.

Comparisons among the analysis results by CUFSM, the predictions of the Chinese code [22], and Eq. (7) are shown in Fig. 13. The proposed formula provides more accurate predictions than the Chinese design code in calculating the interactive factor. The Chinese code [22] gives unsafe predictions as the ratio of $B / H$ is higher than 0.8 .

For circular hollow sections, the critical local buckling moment $M_{\mathrm{crl}}$ can be approximately calculated using Eq. (8) [36].

$$
M_{c r l}=\frac{E}{\sqrt{3\left(1-v^{2}\right)}} \frac{t}{R} W
$$

where $M_{\mathrm{crl}}, E, v, t, W$ are consistent with those in Eq.(6), and $R$ is the radius of the cross section.

\section{Comparisons of the test strengths with the design strengths}

\subsection{Current design codes}

\subsubsection{Eurocode (EN 1993-1-4:2006/A1:2015)}

In the Eurocode[19], cross sections are classified into four classes according to their plastic behaviors. For Class 1 and Class 2, bending capacity was calculated using the plastic section modulus. For Class 3, the elastic section modulus is used. For Class 4 whose failure is dominated by local buckling, the effective cross section modulus is used. Eq. (9) shows the design formula. 


$$
M_{\mathrm{c}, \mathrm{Rd}}= \begin{cases}\frac{W_{p l} f_{y}}{\gamma_{M 0}} & \text { for Class 1 and Class 2 } \\ \frac{W_{e l, \min } f_{y}}{\gamma_{M 0}} & \text { for Class 3 } \\ \frac{W_{e f f, \min } f_{y}}{\gamma_{M 0}} & \text { for Class 4 }\end{cases}
$$

where $M_{\mathrm{c}, \mathrm{Rd}}$ is the design bending capacity, $W_{\mathrm{pl}}$ is the plastic section modulus, $W_{\mathrm{el}, \mathrm{min}}$ is the minimum elastic section modulus, $W_{\text {eff,min }}$ is the minimum effective section modulus, $f_{\mathrm{y}}$ is the nominal yield stress, and $\gamma_{\mathrm{M} 0}$ is the partial factor. Table 6 shows the classification limits. In this table, $c$ is the width of the web or the flange, $t$ is the thickness; $d$ is the diameter of the circular cross section; $\varepsilon$ is the material factor, calculated using $\left(235^{*} E / f_{\mathrm{y}} / 210000\right)^{0.5}$.

\subsubsection{American code (SEI/ASCE 8-02)}

In the American code [20], two design methods are specified for rectangular hollow section. One is based on the initial yielding assumption, while the other one utilizes the inelastic reserve capacity brought about by the spread of plasticity through the section. The second method was employed in this paper. In the second method, the maximum compression strain is defined by $C_{\mathrm{y}} \times f_{\mathrm{y}} / E_{0}$. $C_{\mathrm{y}}$ is the compression strain factor, calculated by using Eq. (10).

$$
C_{\mathrm{y}}= \begin{cases}3 & w / t \leq \lambda_{1} \\ 3-2\left(\frac{w / t-\lambda_{1}}{\lambda_{2}-\lambda_{1}}\right) & \lambda_{1}<w / t<\lambda_{2} \\ 1 & w / t \geq \lambda_{2}\end{cases}
$$

where $w$ is the width of the compression flange, $t$ is the thickness of the flange, $\lambda_{1}$ is calculated using $1.11 /\left(f_{\mathrm{y}} / E\right)^{0.5}$, and $\lambda_{2}$ is calculated using $1.28 /\left(f_{\mathrm{y}} / E\right)^{0.5}$. The bending capacity is then calculated by integrating the stress along the cross-section based on the elastic-perfect-plastic material assumption and plane section assumption. The maximum bending capacity should not exceed $1.25 M_{\mathrm{e}}$. For 
circular hollow sections, plastic design is not allowed, and a linear interpolation is used to account for the effectiveness of the cross-section when the $D / t$ ratio is beyond a certain limit (see Eq. (11)).

$$
M_{n}= \begin{cases}f_{y} S_{f} & \frac{D}{t} \leq \frac{0.112 E}{f_{y}} \\ K_{c} f_{y} S_{f} & \frac{0.112 E}{f_{y}} \leq \frac{D}{t} \leq \frac{0.881 E}{f_{y}}\end{cases}
$$

where $D$ is the diameter of the circular hollow section, $S_{\mathrm{f}}$ is the elastic section modulus of full, unreduced cross sections, and $K_{\mathrm{c}}$ is the reduction factor calculated by Eq. (12).

$$
K_{c}=\frac{(1-C)\left(E / f_{y}\right)}{\left(8.93-\lambda_{c}\right)(D / t)}+\frac{5.882 C}{8.93-\lambda_{c}}
$$

where $C$ is the ratio of the proportionality stress-to-yield stress, and $\lambda_{\mathrm{c}}$ is equal to $3.048 C$.

\subsubsection{Australian/New Zealand code(AS/NZS 4673-2001)}

In Australian/New Zealand code[21], the design process of the bending capacity is similar to that in the American code. For rectangular hollow sections, the upper limits of bending capacity is the plastic moment $\left(f_{\mathrm{y}} S_{\mathrm{p}}\right)$ instead of $1.25 M_{\mathrm{e}}$ for the stocky cross sections with $w / t$ less than $\lambda_{1}$. For circular hollow sections, the upper limits of bending capacity is the plastic moment $\left(f_{\mathrm{y}} S_{\mathrm{p}}\right)$. An interpolation formula is used to consider the effective cross-section properties (see Eq. (14)). Eq. (13) and Eq. (14) show formulas used to calculate bending capacity of circular hollow sections in the Australian/New Zealand codes. The symbols in these equations have the same meanings as those in Eq. (11) and Eq. (12). 


$$
\begin{gathered}
M_{n}= \begin{cases}f_{y} S_{p} & \frac{D}{t} \leq \frac{0.078 E}{f_{y}} \\
f_{y} S_{f} & \frac{0.078 E}{f_{y}} \leq \frac{D}{t} \leq \frac{0.31 E}{f_{y}} \\
K_{c} f_{y} S_{f} & \frac{0.31 E}{f_{y}} \leq \frac{D}{t} \leq \frac{0.881 E}{f_{y}}\end{cases} \\
K_{c}=\frac{(1-C)\left(E / f_{y}\right)}{\left(3.226-\lambda_{c}\right)(D / t)}+\frac{0.178 C}{3.226-\lambda_{c}}
\end{gathered}
$$

\subsubsection{Chinese code (CECS 410:2015)}

In the Chinese code [22], the plastic design for RHS is not allowed currently. Effective width method is adopted to account for the effectiveness of the slender section. When the $b / t$ ratio is beyond the limits listed in Table 7, the reduction factor should be calculated according to Eq. (15).

$$
\frac{b_{e}}{t}= \begin{cases}\left(2.41-1.63 \sqrt{\lambda_{\mathrm{p}}}\right) \frac{b_{\mathrm{c}}}{t} \leq \frac{b_{\mathrm{c}}}{t} & \bar{\lambda}_{\mathrm{p}} \leq 1.0 \\ \left(\frac{\bar{\lambda}_{\mathrm{p}}}{3.15 \bar{\lambda}_{\mathrm{p}}-1.86}\right) \frac{b_{\mathrm{c}}}{t} & 1.0<\bar{\lambda}_{\mathrm{p}} \leq 1.5 \\ \left(\frac{0.092 \bar{\lambda}_{\mathrm{p}}+0.65}{\bar{\lambda}_{\mathrm{p}}}\right) \frac{b_{\mathrm{c}}}{t} & \bar{\lambda}_{\mathrm{p}}>1.5\end{cases}
$$

where $b_{\mathrm{c}}$ is the width of the plate in compression, $b_{\mathrm{e}}$ is the effective width of the plate, $t$ is the thickness of the plate, $\bar{\lambda}_{\mathrm{p}}$ is the slenderness of the plate, equal to $\left(\sigma / \sigma_{\mathrm{cr}}\right)^{0.5}, \sigma$ is the maximum stress in the plate, and $\sigma_{\mathrm{cr}}$ is the critical buckling stress of the plate, calculated according to Eq.(16).

$$
\sigma_{\mathrm{cr}}=\frac{k k_{1} \pi^{2} E_{0}}{12\left(1-v^{2}\right)}\left(\frac{t}{b}\right)^{2}
$$

where $b$ is the total width of the plate, $k$ is the buckling factor ( 4 for the flange, and 23.87 for the web), and $k_{1}$ is the interactive factor between the web and the flange calculated using Eqs. (17) and (18). 


$$
\begin{gathered}
k_{1}= \begin{cases}\frac{1}{\sqrt{\xi}} & \xi \leq 1.1 \\
0.11+\frac{0.93}{(\xi-0.05)^{2}} & \xi>1.1\end{cases} \\
\xi=\frac{c}{t_{\mathrm{c}}} \frac{t_{\mathrm{b}}}{b} \sqrt{\frac{k}{k_{\mathrm{c}}}}
\end{gathered}
$$

where $c, t_{\mathrm{c}}$, and $k_{\mathrm{c}}$ are the width, the thickness, and the buckling factor of the plate next to the plate being calculated. For example, when calculating the interactive factor of the web to the flange, $c, t_{\mathrm{c}}$, and $k_{\mathrm{c}}$ are the width, the thickness, and the buckling factor of the web, respectively. For the CHS, yield moment is used for sections within the limits given in Table 7.

\subsubsection{DSM method}

Huang and Young [10] did tests and numerical simulations on the lean duplex stainless steel rectangular cross section and improved the DSM formula in North American Specification for the Design of Cold-formed Steel Structural Members [27], as shown in Eq. (19).

$$
M_{D S M}= \begin{cases}1.1\left(\left(0.776-\lambda_{1}\right)+1\right) M_{y} & \lambda_{l} \leq 0.776 \\ \left(1-0.15\left(\frac{M_{c r l}}{1.1 M_{y}}\right)^{0.4}\right)\left(\frac{M_{c r l}}{1.1 M_{y}}\right)^{0.4} 1.1 M_{y} & \lambda_{l}>0.776\end{cases}
$$

where $M_{\mathrm{y}}$ is the yield moment of the cross-section, $M_{\mathrm{cr}}$ is the critical elastic local buckling moment, and $\lambda_{l}$ is the section slenderness.

\subsubsection{CSM method}

Gardner's group [23-26] developed the continuous strength method (CSM) to utilize the strain hardening property of stainless steel. The CSM method is a strain based design approach featuring two key components: (1) a base curve that defines the level of strain that a cross-section can carry 
in a normalized form, and (2) a material model, which allows for strain hardening and, in conjunction with the strain measurement, can be used to determine the cross-section bending resistance. The base curve for rectangular and circular hollow sections is given by Eq. (20)[25] and Eq. (21)[26], while the material model is shown in Eqs. (22), (23) and (24).

$$
\begin{aligned}
& \frac{\varepsilon_{\mathrm{csm}}}{\varepsilon_{y}}=\frac{0.25}{\lambda_{p}^{3.6}} \leq \min \left(15, \frac{C_{1} \varepsilon_{u}}{\varepsilon_{y}}\right) \\
& \frac{\varepsilon_{\mathrm{csm}}}{\varepsilon_{y}}= \begin{cases}\frac{4.44 \times 10^{-3}}{\lambda_{\mathrm{c}}^{4.5}} \leq\left(15, \frac{C_{1} \varepsilon_{u}}{\varepsilon_{y}}\right) & \lambda \leq 0.3 \\
\left(1-\frac{0.224}{\lambda_{\mathrm{c}}^{0.342}}\right) \frac{1}{\lambda_{\mathrm{c}}^{0.342}} & 0.3 \leq \lambda<0.6\end{cases} \\
& \sigma= \begin{cases}E \varepsilon & \sigma \leq f_{y} \\
E \varepsilon+E_{s h}\left(\varepsilon-\varepsilon_{y}\right) & \sigma>f_{y}\end{cases} \\
& E_{s h}=\frac{f_{u}-f_{y}}{C_{2} \varepsilon_{u}-\varepsilon_{y}} \\
& \varepsilon_{u}=C_{3}\left(1-\frac{f_{y}}{f_{u}}\right)+C_{4}
\end{aligned}
$$

where, $\varepsilon_{\mathrm{csm}}$ is the maximum compression strain that the cross section can carry, $\varepsilon_{\mathrm{y}}$ is the yield strain $\left(f_{\mathrm{y}} / E\right), \varepsilon_{\mathrm{u}}$ is the ultimate tensile strain, $\lambda_{\mathrm{p}}$ is the slenderness of rectangular hollow sections, $\lambda_{\mathrm{c}}$ is the slenderness of circular hollow sections, $E_{\mathrm{sh}}$ is the tangent elastic modulus of the material as the stress is beyond the nominal yield stress, and $C_{1}, C_{2}, C_{3}$, and $C_{4}$ are parameters, related to the types of material. For austenitic and duplex stainless steel, $C_{1}, C_{2}, C_{3}$, and $C_{4}$ are taken as $0.1,0.16,1.0$, and 0 , respectively. For ferritic stainless steel, $C_{1}, C_{2}, C_{3}$, and $C_{4}$ are $0.4,0.45,0.6$, and 0 , respectively.

\subsection{Comparisons}

Test data on bending capacities of rectangular and circular hollow sections were collected from literatures and compared with current design codes including, the Eurocode, the American code, the 
Australian/New Zealand code, and the Chinese code, as well as the CSM method, and the proposed method. Several notes should be made before the comparisons: (1) The partial factors ( $\gamma_{\mathrm{M} 0}$ and $\left.\phi\right)$ were set to 1.0. (2) Tensile material properties from corresponding tests were used in calculations. (3) When using the Eurocode, the corner enhancement of rectangular hollow section was considered in the capacity prediction for Class 1, Class 2, and Class 3 cross-sections. (4) When using the American code, the increase of yield stress in the corner region was ignored for all the cross sections according to the related provisions in the code. (5) When using the Chinese code, corner enhancement was neglected for all the cross sections. (6) When calculating the yield moment $M_{\mathrm{y}}$ for the DSM method proposed by Huang, cold working effect in the corner region was neglected, since the factor 1.1 in Eq.(19) has been used to include the corner enhancement. (7) When calculating the section slenderness for the CSM and DSM methods proposed by this paper, the cold working effect in the corner region was included in the yield moment $M_{\mathrm{yc}} .\left(M_{\mathrm{yc}}=\sigma_{\mathrm{f}} \times W_{\mathrm{f}}+\sigma_{\mathrm{c}} \times W_{\mathrm{c}}\right.$, in which, $\sigma_{\mathrm{f}}$ and $\sigma_{\mathrm{c}}$ are the nominal yield stress of the flat and corner region, respectively, and $W_{\mathrm{f}}$ and $W_{\mathrm{c}}$ are the elastic section modulus of the flat and corner region, respectively.).

Calculation results are shown in Table 8 and Table 9 for rectangular and circular hollow sections, respectively. In these two tables, $M_{\mathrm{en}}, M_{\mathrm{asce}}, M_{\mathrm{au}}, M_{\mathrm{cn}}, M_{\mathrm{csm}}, M_{\mathrm{h}}$, and $M_{\mathrm{p}}$ are the predicted bending capacity by using the Eurocode, the American code, the Australian/New Zealand code, the Chinese code, the CSM method, the DSM formula proposed by Huang, and DSM formula proposed by this paper, respectively.

From Table 8, it can be concluded that: (1) All the seven design methods are conservative in predicting the bending capacity of rectangular hollow sections. (2)The Chinese code gives the 
highest ratio of the test results over the predicted values, with the mean value of 1.48 and large scatter of 0.26. The American code, the Australian/New Zealand code, the Eurocode, and the CSM method show good performance in the ascending order. (3) The DSM formula proposed by Huang provides good predictions with the mean value 1.07. The proposed DSM method gives the most accurate predictions. The major difference between these two DSM formulas is the upper limit of the bending capacity. The upper limit of Eq.(19) is $1.85 M_{\mathrm{y}}$, while Eq.(3) adopts $\sigma_{\mathrm{u}} W_{\mathrm{u}}$ as the maximum value of bending capacity.

Fig.14 shows the ratios of the test results over the predictions by Eurocode and Chinese code. It indicates that: (1) Chinese code shows good predictions for specimens with slenderness higher than 0.75, which is the limit beyond which the effectiveness of the section should be considered. (2) Chinese code gives more conservative predictions for Class 1 and Class 2 sections. That is because Chinese code uses the yield moment, while the Eurocode adopts the plastic moment for Class 1 and Class 2 sections. (3) For Class 3 and Class 4 sections with slenderness ranging from 0.62 to 0.75 , the two codes show similar performance.

Test data collected were also plotted in Fig. 10 together with the finite element results and the proposed strength curve. It can be concluded that: (1) Most of the test data points lie above of the line $M_{\mathrm{u}} / M_{\mathrm{yc}}=1.0$ which demonstrates that the strain hardening considerably contributes to the bending capacity of the stainless steel members. (2) Test data points of members of austenitic and duplex stainless steel show the same trend, a little bit above the proposed strength curve, while test data points of ferritic stainless steel members lie below the proposed strength curve. So, the 
proposed curve gives unsafe predictions for ferritic stainless steel members. Compared with austenitic stainless steel and duplex stainless steel, ferritic stainless steel has low ratio of $\sigma_{\mathrm{u}} / \sigma_{\mathrm{y}}$, which is the main reason for the different performance of austenitic and duplex stainless steel members to the ferritic stainless steel members. (3) Due to different strengthening methods used in tests to prevent premature local buckling at the loading points, test data points with similar section slenderness scatter in a considerable range.

From Table 9, we can conclude that: (1) the American code provides the most conservative predictions followed by Chinese code, with the ratio of test versus predictions as 1.48 and 1.41 , respectively. These two codes do not allow plastic design for circular hollow sections. And the effectiveness of the cross-section is considered when the $D / t$ ratio is beyond certain limits according to the American code. (2) The Eurocode and the Australian/New Zealand code provide the same predictions for all the test specimens. That is because the section slenderness limit for Class 2 and Class 3 in the Eurocode is almost the same with the limit for the plastic /elastic design in the Australian/New Zealand code. (3) CSM method gives good predictions for specimens with section slenderness higher than 0.3 , while for the case when the slenderness is less than 0.3 , this method shows very conservative predictions. (4) The proposed method provides good predictions on the safe side, with the mean ratio (test over predictions) of 1.11 and the scatter of 0.09 .

Test data of circular hollow members are also plotted in Fig. 11 together with finite element analysis results and the proposed strength curve. Due to the strain hardening of stainless steel, the ratios of the test results over yield moments are higher than 1.0 for most of the test specimens. The proposed 
curve lies on the lower boundary of the test data. It provides better predictions for the test specimens with section slenderness less than 0.35 .

\section{Conclusions}

A series of tests on the bending capacity of stainless steel rectangular and circular hollow sections were reported. Material properties, geometric imperfections, bending capacities, and momentcurvature curves were obtained. Finite element models were built and validated for the test specimens. Two kinds of finite element models based on full-length members and pure bending segment of members provide almost the same bending capacity, which is about $5 \%$ lower than the test results due to the friction between the knife-hinge and the strengthen rig in the test. Parameter analysis were conducted to consider the influence of section slenderness and material properties on bending capacity. DSM formulas were proposed by fitting the finite element results for rectangular and circular hollow sections, respectively. Test data collected from literatures were compared with the predictions of current design codes and the proposed method. Comparisons show that the Eurocode, the American code, the Australian/New Zealand code, and the Chinese code provide conservative predictions for both rectangular and circular hollow sections. CSM method shows better predictions than the design codes. The Chinese code provides very good predictions for slender rectangular sections, but generates the most conservative predictions for stocky cross sections due to the neglect of strain hardening effect and section plasticity. The proposed method provides safe and accurate predictions for the bending capacity of austenitic and duplex stainless steel hollow members. The average ratio and the standard deviation of the test results over the predicted strengths are 1.04 and 0.10 for rectangular hollow members, and 1.11and 0.09 for circular 
hollow members. The behaviors of ferritic stainless steel members are different from that of austenitic and duplex stainless steel members and the proposed formulas were not applicable. More work need to be done on the bending capacity of ferritic stainless steel members.

\section{Acknowledgements}

The research work described in this paper is supported by the Priority Academic Program Development of Jiangsu Higher Education Institutions and by the National Science Foundation of China through the projects No. 51178098, No. 51378105 and 51578134. The financial support is highly appreciated. Special thanks to the Jiangsu Dongge Stainless steel Ware Co., Ltd. for providing the test specimens.

\section{Reference}

[1] Johnson A.L., Winter G. Behavior of stainless steel columns and beams. Journal of the Structural Division, ASCE, 1966, 92(5): 97-118.

[2] Rasmussen K.J.R., Hancock G.J. Design of cold-formed stainless steel tubular members. II: beams. Journal of Structural Engineering, ASCE, 1993, 119(8): 2368-2386.

[3] Talja A., Salmi P. Design of stainless steel RHS beams, columns and beam-columns. Research Note 1619. VTT Building Technology, Finland, 1995.

[4] Real E., Mirambell E. Flexural behavior of stainless steel beams. Engineering Structures, 2005, 27: 1465-1475.

[5] Gardner L. A new approach to stainless steel structural design. PhD Thesis. Structures Section. Department of Civil and Environmental Engineering, Imperial College, London, 2002. 
[6] Gardner L., Talja A., and Baddoo N.R. Structural design of high-strength austenitic stainless steel. Thin-Walled Structures, 2006, 44: 517-528.

[7] Zhou F., Young B. Tests of cold-formed stainless steel tubular flexural members. Thin-Walled Structures, 2005, 43:1325-1337.

[8] Theofanous M., Gardner L. Experimental and numerical studies of lean duplex stainless steel beams. Journal of Constructional Steel Research, 2010, 66:816-825.

[9] Zheng B.F., Shen X.M., Xin L.C., and Shu G.P. Test on the Bending Capacity of ColdFormed Stainless Steel Rectangular Hollow Sections. Eighth International Conference on Steel and Aluminum Structures, Hong Kong, China, 2016. (In press).

[10] Huang Y., Young B. Experimental and numerical investigation of cold-formed lean duplex stainless steel flexural members. Thin-Walled Structures, 2013, 73:216-228.

[11] Afshan S., Gardner L. Experimental study of cold-formed ferritic stainless steel hollow sections. Journal of Structural Engineering, 2013, 139(5):717-728.

[12] Bock M., Arrayago I., Real E. Experiments on cold-formed ferritic stainless steel slender sections. Journal of Constructional Steel Research, 2015, 109:13-23.

[13] Theofanous M., Saliba N., Zhao O. Gardner L. Ultimate response of stainless steel continuous beams. Thin-Walled Structures, 2014, 83:115-127.

[14] Zhao O., Rossi B., Gardner L., Young B. Behavior of structural stainless steel cross-sections under combined loading-Part I: Experimental study. Engineering Structures, 2015, 89: 236246. 
[15] Zhao O., Rossi B., Gardner L., Young B. Experimental and numerical studies of ferritic stainless steel tubular cross sections under combined compression and bending. Journal of structural engineering, 2016, 142(2):04015110.

[16] Zhao O., Gardner L., Young B. Buckling of ferritic stainless steel members under combined axial compression and bending. Journal of Constructional Steel Research, 2016, 117:35-48.

[17] Kiymaz G. Strength and stability criteria for thin-walled stainless steel circular hollow section members under bending. Thin-Walled Structures, 2005, 43:1534-1549.

[18] Way J. Structural design of stainless steel circular hollow sections. Report to ECSC. The Steel Construction Institute, 2000.

[19] EC3. Eurocode 3: Design of steel structures-Part 1.4: General rules-supplementary rules for stainless steels. European Committee for Standardization, EN 1993-1-4:2006/A1:2015, CEN, Brussels; 2015.

[20] ASCE. Specification for the design of cold-formed stainless steel structural members. American Society of Civil Engineers, SEI/ASCE-8-02, Reston, Virginia, 2002.

[21] AS/NZS. Cold-formed stainless steel structures. Australian/New Zealand-Standard, AS/NZS 4673:2001, Standards Australia, Sydney, Australia, 2001.

[22] CECS. Technical specification for stainless steel structures. China Association for Engineering Construction Standardization, CECS 410:2015, China planning press, Bejing China, 2015.

[23] Ashraf M., Gardner L., and Nethercot D.A. Structural stainless steel design: resistance based on deformation capacity. Journal of Structural Engineering, 2008,134 (3):402-411.

[24] Gardner L., Theofanous M. Discrete and continuous treatment of local buckling in stainless steel elements. Journal of Constructional Steel Research, 2008, 64: 1207-1216. 
[25] Afshan S., Gardner L. The continuous strength method for structural stainless steel design. Thin-Walled Structures, 2013, 68:42-49.

[26] Buchanan C., Gardner L., Liew A. The continuous strength method for the design of circular hollow sections. Journal of Constructional Steel Research, 2016, 118:207-216.

[27] AISI. North American specification for the design of cold-formed steel structural members. AISI S100-2007, North American Cold-formed Steel Specification. American Iron and Steel Institute, Washington, D.C. 2007.

[28] GB/T 20878-2007.Stainless and heat-resisting steels-Designation and chemical compositions. China Standard Press, Beijing, 2007 (in Chinese).

[29] GB/T 228.1-2010. Metallic materials-tensile testing-Part 1: Method of test at room temperature. China Standard Press, Beijing, 2010 (in Chinese).

[30] ABAQUS. ABAQUS/Standard User's Manual, Version 6.7. Pawtucket, RI; 2007.

[31] Gardner L., Cruise R.B. Modeling of residual stresses in structural stainless steel sections. Journal of Structural Engineering, 2009, 135(1):42-53.

[32] Ashraf M., Gardner L., Nethercot D.A. Finite element modelling of structural stainless steel cross-sections. Thin-Walled Structures, 2006, 44:1048-1062.

[33] Quach, W.M., Teng, J.G. and Chung, K.F. Three-stage Full-range Stress-strain Model for Stainless Steels. Journal of Structural Engineering, 2008, Vol. 134, No. 9, pp. 1518-1527.

[34] Schafer B.W., Adany S. Buckling analysis of cold-formed steel members using CUFSM: Conventional and Constrained Finite Strip Methods. In: Proceedings of the eighteenth international specialty conference on cold-formed steel structures. Orlando, FL, USA, 2006, $39-54$ 
[35] Li Z., Schafer B.W. Application of the finite strip method in cold-formed steel member design. Journal of Constructional Steel Research, 2010, 66(8-9): 971-980.

[36] Timoshenko S. Theory of elastic stability $2^{\text {nd }}$ edition, McGraw-Hill, 1961. 


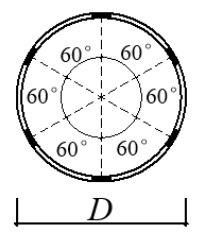

CHS $89 \times 3$

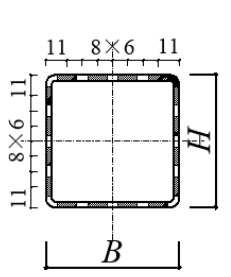

SHS $70 \times 3$

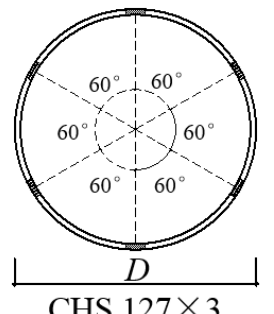

Coupon

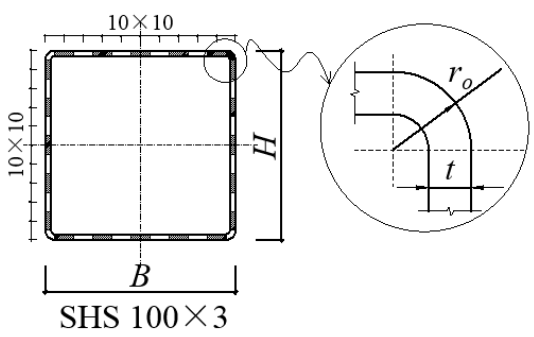

Figure 1 Definitions of symbols and locations of coupons in cross-sections
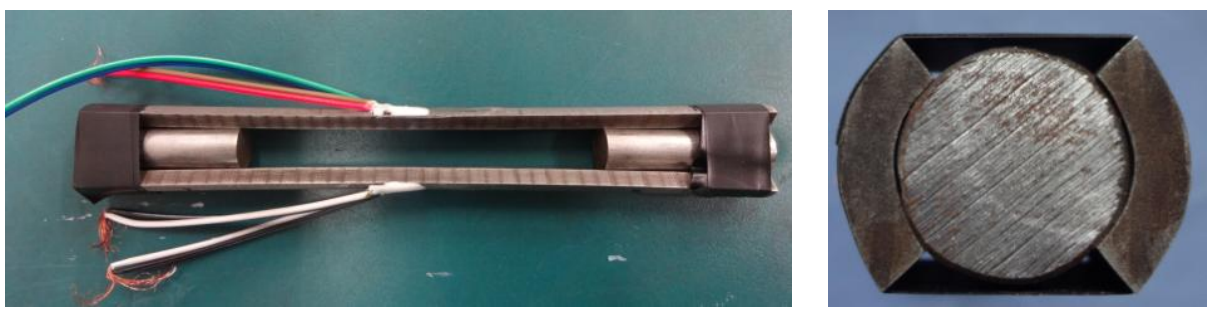

Figure 2 Corner coupons

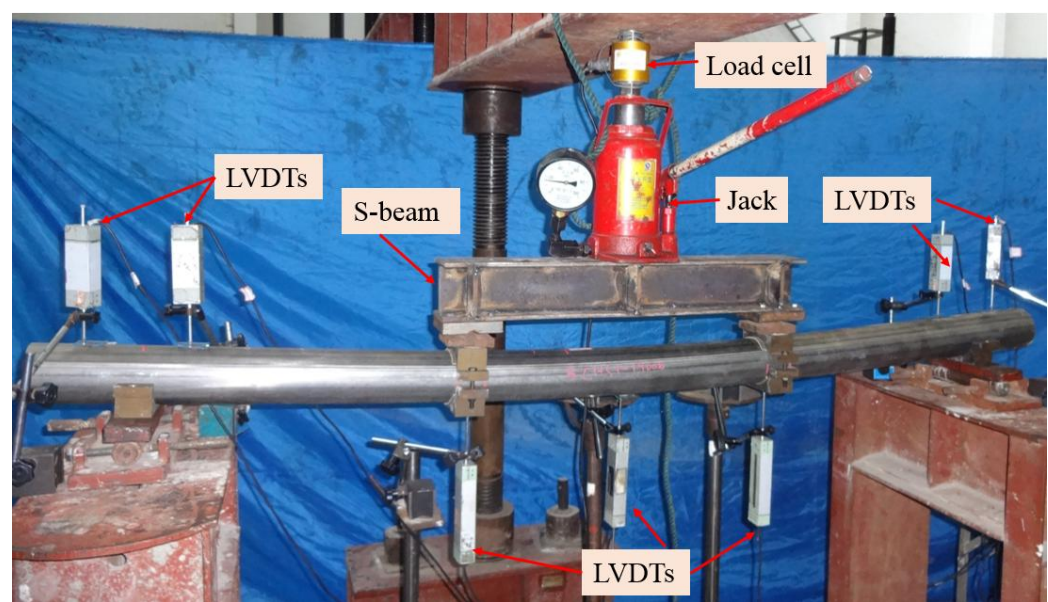

Figure 3 Layout of the four-point bending test 


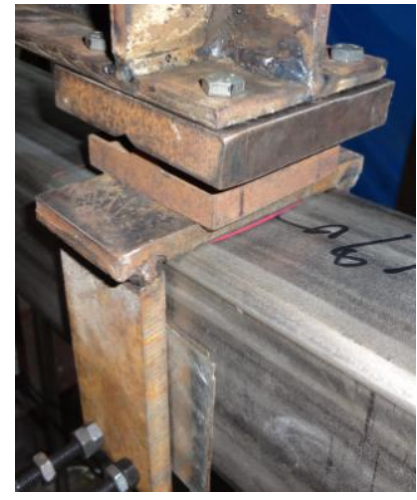

(a) Steel plate

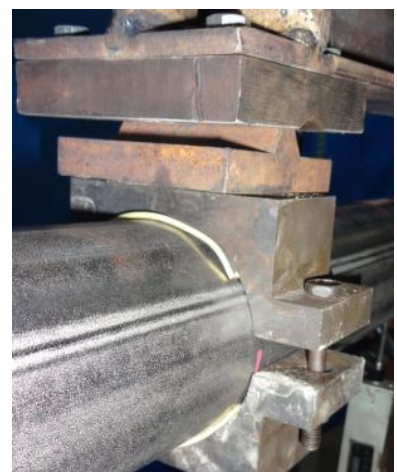

(b) Steel ring

Figure 4 Steel plate and steel ring at the loading point

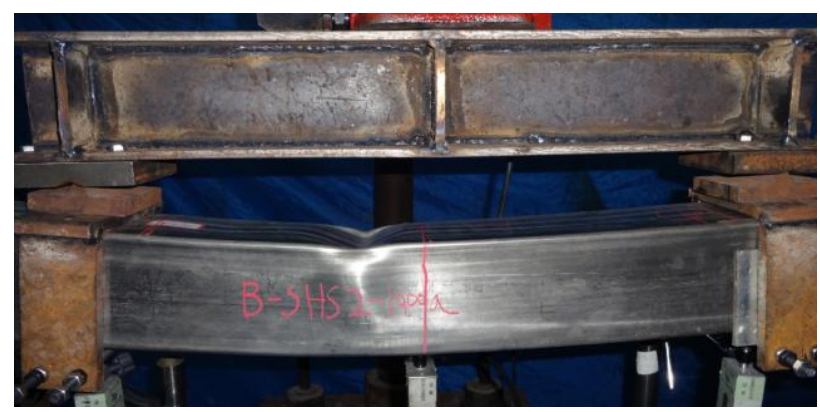

(a) Rectangular hollow section (SHS100×3-1900a)

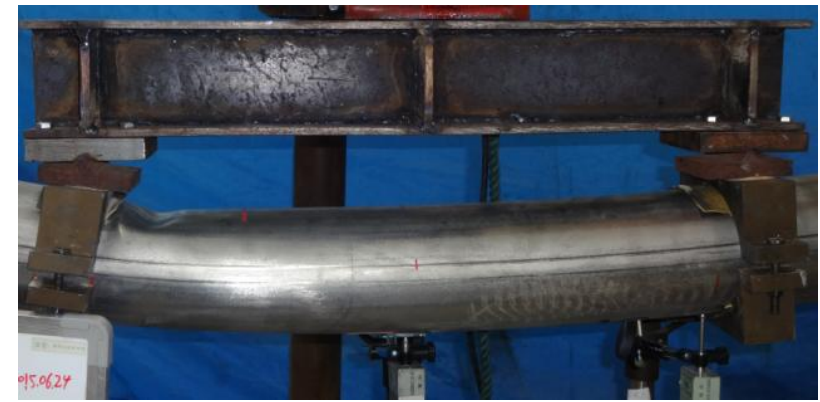

(b) Circular hollow section (CHS127×3-1900a)

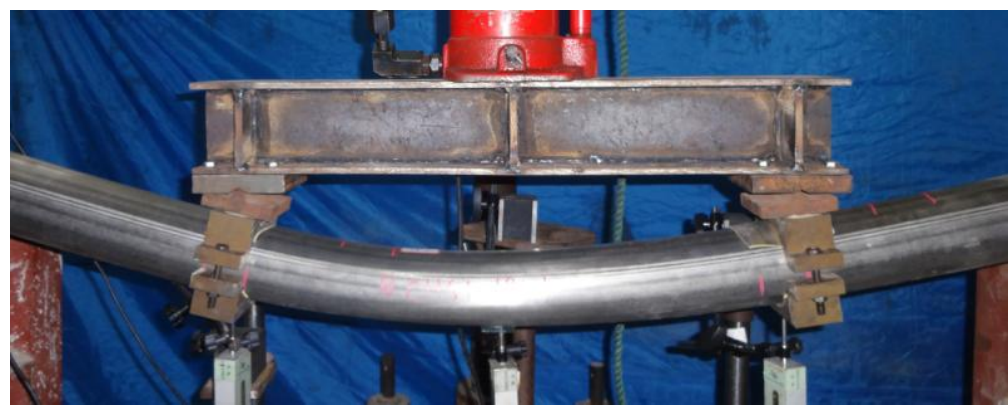

(c) Circular hollow section (CHS89×3-1900b)

Figure 5 Failure modes of test specimens 


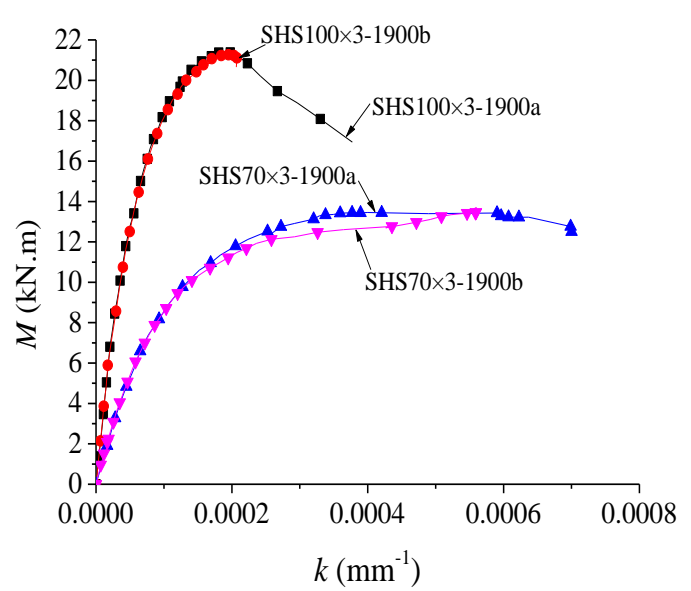

(a) Rectangular hollow section

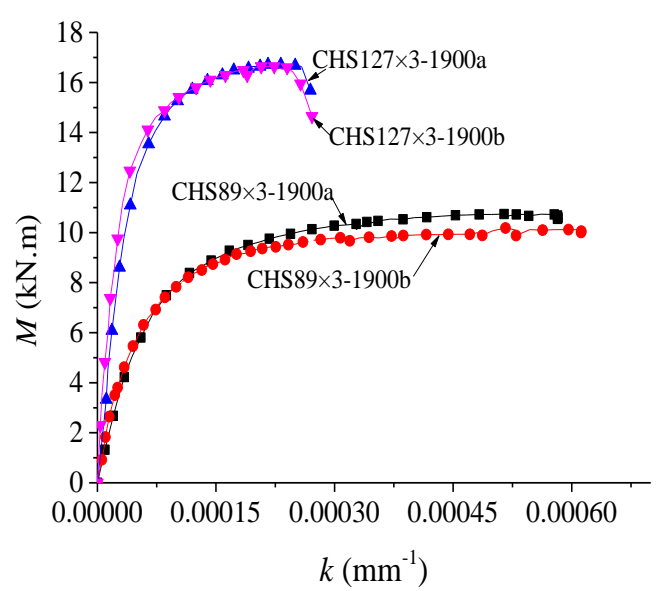

(b) Circular hollow section

Figure 6 Moment-Curvature curves of test specimens

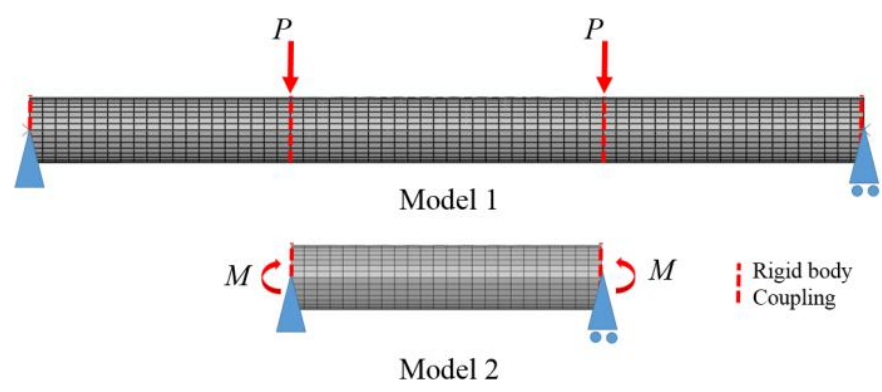

Figure 7 Boundary conditions in the finite element models

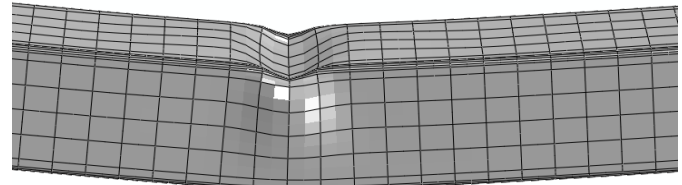

(a) Rectangular hollow section (SHS100×3-1900a)

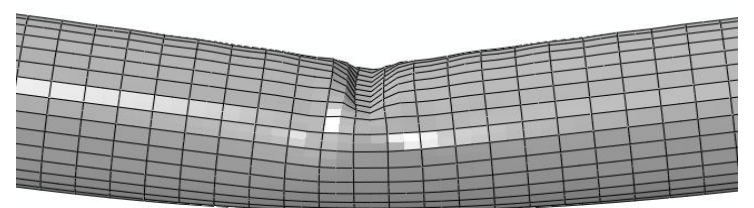

(b) Circular hollow section (CHS127×3-1900a)

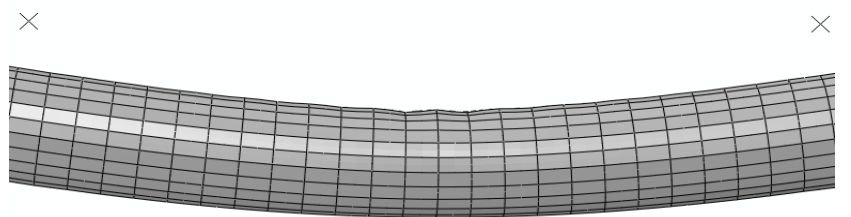

(c) Circular hollow section (CHS89×3-1900b)

Figure 8 Failure modes predicted using FEM 


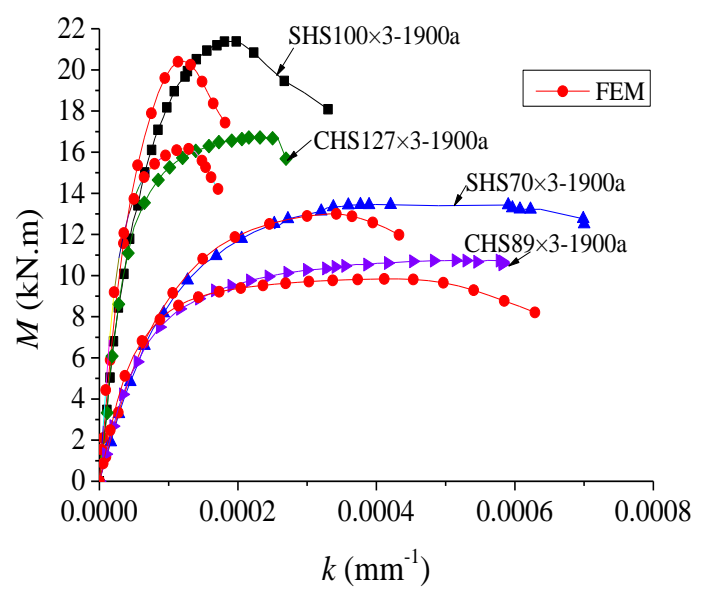

Figure 9 Comparison of experimental and simulation (Model 1) moment-curvature curves

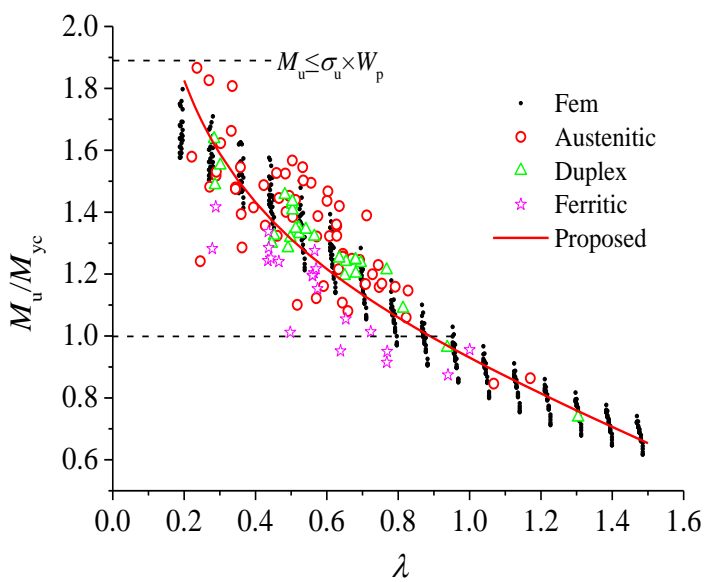

Figure 10 Comparisons of the test data and the finite element results with the predictions of the proposed DSM formula for rectangular hollow sections

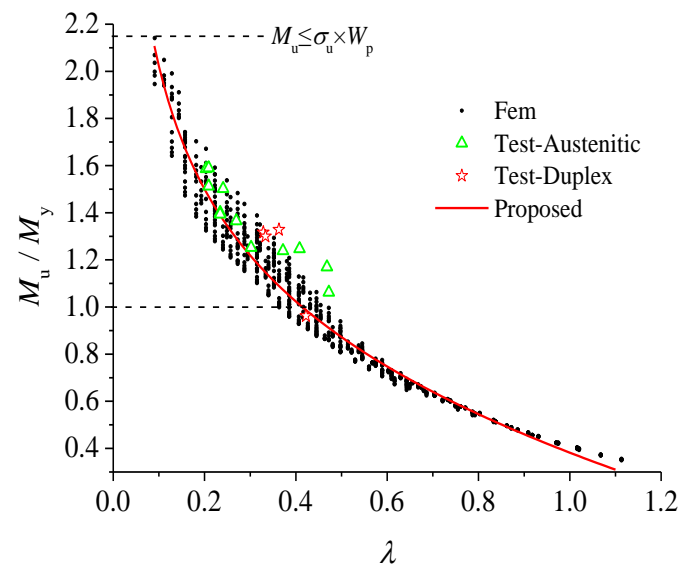

Figure 11 Comparisons of the test data and the finite element results with the predictions of the proposed DSM formula for circular hollow sections 


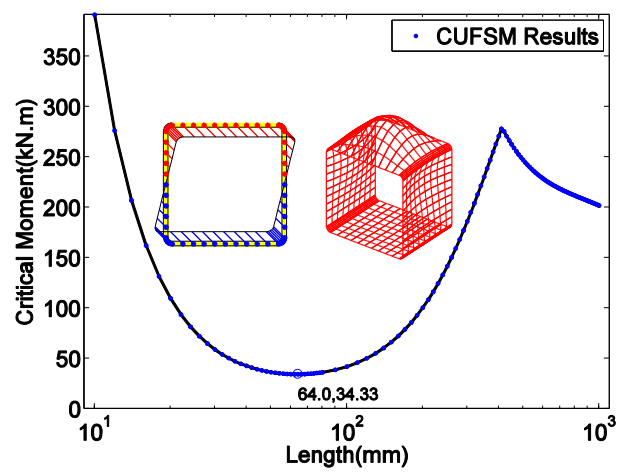

Figure 12 Typical output of the CUFSM for RHS subjected pure bending

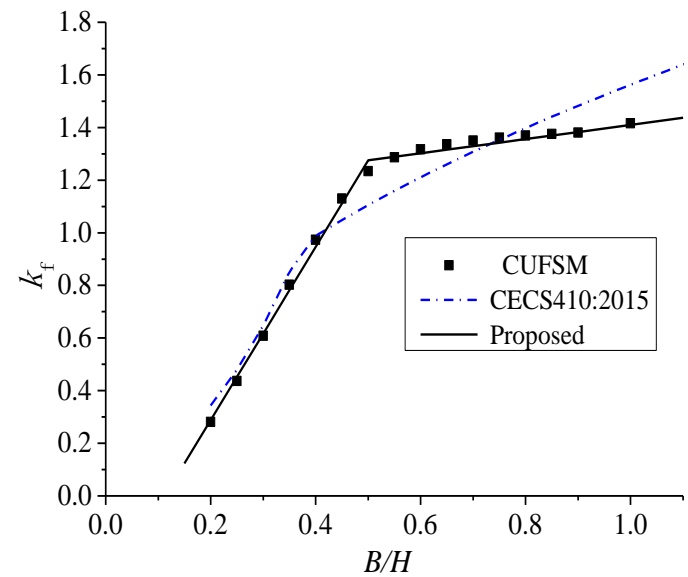

Figure 13 Comparisons of the analysis results and the predictions of the design code and the proposed formula for the interactive factor

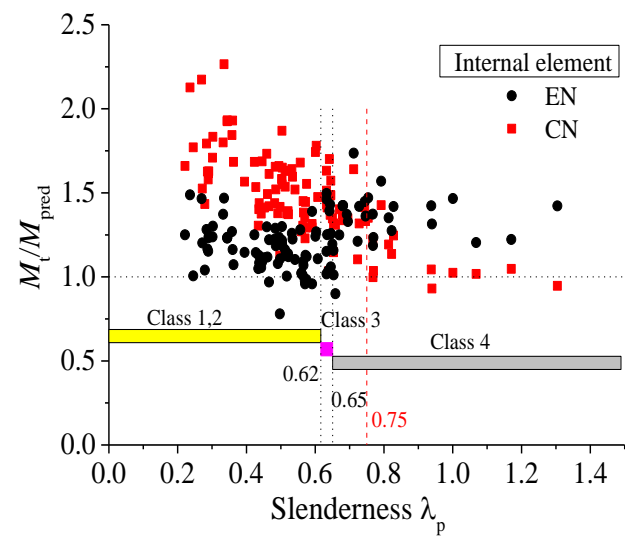

Figure 14 Comparisons of the Eurocode and the Chinese code with the test data 
Table 1 Weighted average tensile material properties of virgin plates

\begin{tabular}{|c|c|c|c|c|c|c|c|}
\hline Cross section & $E_{0}$ & $\sigma_{0.2}$ & $\sigma_{1.0}$ & $\sigma_{\mathrm{u}}$ & $n$ & $n_{0.2,1.0}$ & $\delta$ \\
\hline SHS70×3 & \multirow{2}{*}{176472} & \multirow{2}{*}{243.26} & \multirow{2}{*}{297.85} & \multirow{2}{*}{636.57} & \multirow{2}{*}{3.77} & \multirow{2}{*}{2.25} & \multirow{2}{*}{0.60} \\
\hline CHS89×3 & & & & & & & \\
\hline SHS100×3 & \multirow{2}{*}{187566} & \multirow{2}{*}{231.78} & \multirow{2}{*}{279.35} & \multirow{2}{*}{627.61} & \multirow{2}{*}{4.97} & \multirow{2}{*}{2.11} & \multirow{2}{*}{0.63} \\
\hline CHS127×3 & & & & & & & \\
\hline
\end{tabular}

Table 2 Weighted average tensile material properties of finished tubes

\begin{tabular}{|c|c|c|c|c|c|c|c|c|}
\hline Cross section & Position & $E_{0}$ & $\sigma_{0.2}$ & $\sigma_{1.0}$ & $\sigma_{\mathrm{u}}$ & $n$ & $n_{0.2,1.0}$ & $\delta$ \\
\hline \multirow{2}{*}{ SHS70 $\times 3$} & Flat & 196838 & 489.03 & 586.71 & 771.86 & 3.90 & 3.94 & 0.42 \\
\hline & Corner & 195303 & 620.24 & 781.52 & 895.98 & 4.30 & 4.09 & 0.25 \\
\hline \multirow{2}{*}{ SHS100×3 } & Flat & 193096 & 408.27 & 487.31 & 712.46 & 4.17 & 3.67 & 0.50 \\
\hline & Corner & 194591 & 560.63 & 679.45 & 822.84 & 4.49 & 3.73 & 0.31 \\
\hline CHS $89 \times 3$ & & 201807 & 385.35 & 440.13 & 678.77 & 5.44 & 3.13 & 0.59 \\
\hline CHS127×3 & & 203186 & 329.02 & 375.84 & 648.44 & 6.22 & 2.61 & 0.60 \\
\hline
\end{tabular}

Table 3 Measured dimensions of test specimens

\begin{tabular}{|c|c|c|c|c|c|c|c|}
\hline \multirow{2}{*}{ Specimens } & \multicolumn{5}{|c|}{ Dimensions } & \multicolumn{2}{|c|}{ Imperfections $/ \mathrm{mm}$} \\
\hline & $H / \mathrm{mm}$ & $B / \mathrm{mm}$ & $t / \mathrm{mm}$ & $r_{\mathrm{o}} / \mathrm{mm}$ & $L / \mathrm{mm}$ & Local & Overall \\
\hline SHS70×3-1900a & 71.4 & 71.8 & 3.1 & 6.25 & 1900 & 0.086 & 1.3 \\
\hline SHS70×3-1900b & 71.3 & 71.8 & 3.1 & 6.25 & 1900 & 0.096 & 1.6 \\
\hline SHS100×3-1900a & 102.2 & 102.5 & 3.09 & 5.88 & 1900 & 0.11 & 2.7 \\
\hline SHS100×3-1900b & 102.0 & 102.8 & 3.09 & 5.88 & 1901 & 0.11 & 1.0 \\
\hline CHS89×3-1900a & \multicolumn{2}{|c|}{89.3} & 3.11 & & 1900 & 0.12 & 0 \\
\hline CHS $89 \times 3-1900 b$ & \multicolumn{2}{|c|}{89.15} & 3.11 & & 1900 & 0.12 & 0.5 \\
\hline CHS127×3-1900a & \multicolumn{2}{|c|}{127.8} & 3.04 & & 1900 & 0.30 & 0 \\
\hline CHS127×3-1900b & \multicolumn{2}{|c|}{127.8} & 3.04 & & 1900 & 0.30 & 1.3 \\
\hline
\end{tabular}

Table 4 Results of four-point bending tests

\begin{tabular}{|c|c|c|c|}
\hline Specimens & $F_{\mathrm{t}} / \mathrm{kN}$ & $M_{\mathrm{t}} / \mathrm{kN} . \mathrm{m}$ & Failure mode \\
\hline SHS70×3-1900a & 53.84 & 13.46 & $\begin{array}{l}\text { Outwards bulge in compression flange } \\
\text { adjacent to the steel plate }\end{array}$ \\
\hline SHS70×3-1900b & 54.82 & 13.71 & Extensive plastic deformation \\
\hline SHS100×3-1900a & 85.53 & 21.38 & Central inwards bulge in compression flange \\
\hline SHS100×3-1900b & 85.83 & 21.46 & $\begin{array}{l}\text { Outwards bulge in compression flange } \\
\text { adjacent to the steel plate }\end{array}$ \\
\hline CHS89×3-1900a & 42.96 & 10.74 & Extensive plastic deformation \\
\hline CHS $89 \times 3-1900 b$ & 40.73 & 10.18 & Extensive plastic deformation \\
\hline CHS127×3-1900a & 66.86 & 16.72 & Central inwards bulge in compression portion \\
\hline CHS127 $\times 3-1900 b$ & 66.56 & 16.64 & $\begin{array}{l}\text { Outwards bulge in compression portion } \\
\text { adjacent to the steel plate }\end{array}$ \\
\hline
\end{tabular}


Table 5 Comparisons of test results and finite element analysis results

\begin{tabular}{|c|c|c|c|c|c|}
\hline Specimens & $\begin{array}{c}M_{\mathrm{t}} \\
\text { kN.m }\end{array}$ & $\begin{array}{c}M_{1 \mathrm{u}} \\
\text { kN.m }\end{array}$ & $\begin{array}{c}M_{2 \mathrm{u}} \\
\text { kN.m }\end{array}$ & $M_{\mathrm{t}} / M_{1 \mathrm{u}}$ & $M_{\mathrm{t}} / M_{2 \mathrm{u}}$ \\
\hline SHS70×3-1900a & 13.46 & 13.00 & 13.01 & 1.04 & 1.03 \\
\hline SHS70 $\times 3-1900 b$ & 13.71 & 13.00 & 13.01 & 1.05 & 1.05 \\
\hline SHS100×3-1900a & 21.38 & 20.42 & 20.42 & 1.05 & 1.05 \\
\hline SHS100×3-1900b & 21.46 & 20.42 & 20.42 & 1.05 & 1.05 \\
\hline CHS89×3-1900a & 10.74 & 9.84 & 9.85 & 1.09 & 1.09 \\
\hline CHS $89 \times 3-1900 b$ & 10.18 & 9.84 & 9.85 & 1.03 & 1.03 \\
\hline CHS127×3-1900a & 16.72 & 16.17 & 16.25 & 1.03 & 1.03 \\
\hline \multirow[t]{3}{*}{ CHS127×3-1900b } & 16.64 & 16.17 & 16.25 & 1.03 & 1.02 \\
\hline & & & AVG. & 1.05 & 1.05 \\
\hline & & & COV.. & 0.02 & 0.02 \\
\hline
\end{tabular}

Table 6 The classification limits for cold-formed stainless steel hollow sections in the

\begin{tabular}{|c|c|c|c|}
\hline \multicolumn{4}{|c|}{ Eurocode } \\
\hline \multirow{2}{*}{ Limits } & \multicolumn{2}{|c|}{ RHS } & \multirow{2}{*}{ CHS } \\
\hline & Web & Flange & \\
\hline Class 1 & $c / t \leq 72 \varepsilon$ & $c / t \leq 33 \varepsilon$ & $d / t \leq 50 \varepsilon^{2}$ \\
\hline Class 2 & $c / t \leq 76 \varepsilon$ & $c / t \leq 35 \varepsilon$ & $d / t \leq 70 \varepsilon^{2}$ \\
\hline Class 3 & $c / t \leq 90 \varepsilon$ & $c / t \leq 37 \varepsilon$ & $d / t \leq 280 \varepsilon^{2}$ \\
\hline
\end{tabular}

Table 7 The classification limits for cold-formed stainless steel hollow sections in the Chinese

\begin{tabular}{cccc}
\multicolumn{4}{c}{ code } \\
\hline \multirow{2}{*}{ Grades } & \multicolumn{2}{c}{ RHS } & \multirow{2}{*}{ CHS } \\
\cline { 2 - 3 } & Web & Flange & \\
\hline S30403,S31603 & 121 & 49 & 100 \\
\hline S30408,S31608 & 110 & 44 & 90 \\
\hline S22053,S22253 & 74 & 30 & 50 \\
\hline
\end{tabular}


Table 8 Comparisons of test results and predictions of the current design methods and the proposed design method for rectangular hollow sections.

\begin{tabular}{|c|c|c|c|c|c|c|c|c|c|c|}
\hline Ref. & Specimens & Grade & $\lambda$ & $\frac{M_{t}}{M_{\mathrm{en}}}$ & $\frac{M_{t}}{M_{\text {asce }}}$ & $\frac{M_{t}}{M_{\mathrm{au}}}$ & $\frac{M_{t}}{M_{\mathrm{cn}}}$ & $\frac{M_{t}}{M_{\mathrm{csm}}}$ & $\frac{M_{t}}{M_{\mathrm{h}}}$ & $\frac{M_{t}}{M_{\mathrm{p}}}$ \\
\hline 2 & S1B1 & $304 \mathrm{~L}$ & 0.56 & 1.28 & 1.45 & 1.43 & 1.68 & 1.30 & 1.22 & 1.19 \\
\hline \multirow{9}{*}{3} & RHS-1 B1 & \multirow{9}{*}{1.4301} & 0.29 & 1.23 & 1.33 & 1.31 & 1.62 & 1.07 & 0.98 & 0.94 \\
\hline & RHS-1 B2 & & 0.27 & 1.20 & 1.26 & 1.24 & 1.52 & 1.07 & 0.92 & 0.95 \\
\hline & RHS-1 B3 & & 0.29 & 1.24 & 1.34 & 1.32 & 1.62 & 1.08 & 0.99 & 0.95 \\
\hline & RHS-2 B1 & & 0.64 & 1.26 & 1.29 & 1.29 & 1.48 & 1.18 & 1.14 & 1.07 \\
\hline & RHS-2 B2 & & 0.65 & 1.26 & 1.29 & 1.29 & 1.49 & 1.19 & 1.14 & 1.07 \\
\hline & RHS-2 B3 & & 0.64 & 1.26 & 1.29 & 1.29 & 1.48 & 1.18 & 1.14 & 1.07 \\
\hline & RHS-3 B1 & & 0.34 & 1.24 & 1.61 & 1.58 & 1.92 & 1.04 & 1.19 & 0.98 \\
\hline & RHS-3 B2 & & 0.34 & 1.23 & 1.61 & 1.57 & 1.92 & 1.03 & 1.19 & 0.98 \\
\hline & RHS-3 B3 & & 0.34 & 1.23 & 1.60 & 1.57 & 1.92 & 1.03 & 1.19 & 0.97 \\
\hline \multirow{2}{*}{$4 \dagger$} & SHS $80 \times 80$ & \multirow{2}{*}{304} & 0.64 & 1.43 & 1.39 & 1.39 & 1.37 & 1.07 & 1.04 & 0.94 \\
\hline & SHS $80 \times 120$ & & 0.52 & 1.00 & 1.18 & 1.14 & 1.38 & 0.96 & 0.95 & 0.85 \\
\hline \multirow{9}{*}{5} & SHS $80 \times 80 \times 4 B 1$ & \multirow{9}{*}{1.4301} & 0.46 & 1.12 & 1.27 & 1.26 & 1.49 & 1.06 & 1.01 & 0.98 \\
\hline & SHS $100 \times 100 \times 2-B 1$ & & 1.07 & 1.20 & 1.12 & 1.12 & 1.02 & - & 1.00 & 0.95 \\
\hline & SHS $100 \times 100 \times 3-B 1$ & & 0.71 & 1.39 & 1.34 & 1.34 & 1.30 & - & 1.07 & 1.04 \\
\hline & SHS $100 \times 100 \times 4-B 1$ & & 0.57 & 0.96 & 1.06 & 1.05 & 1.23 & 0.98 & 0.91 & 0.90 \\
\hline & SHS $100 \times 100 \times 8-B 1$ & & 0.25 & 1.01 & 1.46 & 1.44 & 1.77 & 0.82 & 1.02 & 0.73 \\
\hline & RHS60×40×40-B1 & & 0.24 & 1.49 & 1.72 & 1.68 & 2.13 & 1.23 & 1.24 & 1.08 \\
\hline & RHS $100 \times 50 \times 2-B 1$ & & 0.59 & 0.96 & 1.09 & 1.07 & 1.31 & 1.01 & 0.98 & 0.95 \\
\hline & RHS100×50×3-B1 & & 0.39 & 1.15 & 1.28 & 1.25 & 1.57 & 1.03 & 1.02 & 0.98 \\
\hline & RHS $100 \times 50 \times 4-B 1$ & & 0.30 & 1.30 & 1.48 & 1.45 & 1.83 & 1.05 & 1.12 & 1.02 \\
\hline \multirow{6}{*}{6} & RHS $100 \times 100 \times 3-A$ & \multirow{6}{*}{$1.4318-\mathrm{C} 850$} & 0.73 & 1.42 & 1.37 & 1.37 & 1.32 & - & 1.11 & 1.08 \\
\hline & RHS $120 \times 80 \times 3-A$ & & 0.61 & 1.11 & 1.24 & 1.22 & 1.47 & 1.18 & 1.12 & 1.09 \\
\hline & RHS $140 \times 60 \times 3-A$ & & 0.51 & 1.16 & 1.32 & 1.29 & 1.63 & 1.14 & 1.14 & 1.11 \\
\hline & RHS $100 \times 100 \times 3-C 850$ & & 0.83 & 1.42 & 1.35 & 1.35 & 1.25 & - & 1.15 & 1.10 \\
\hline & RHS120×80×3-C 850 & & 0.69 & 1.37 & 1.35 & 1.35 & 1.35 & - & 1.10 & 1.09 \\
\hline & RHS $140 \times 60 \times 3-C 850$ & & 0.58 & 1.12 & 1.26 & 1.23 & 1.55 & 1.16 & 1.15 & 1.12 \\
\hline \multirow{11}{*}{7} & $\mathrm{~N} 40 \times 40 \times 2$ & \multirow{8}{*}{304} & 0.43 & 1.14 & 1.31 & 1.29 & 1.53 & 1.06 & 1.01 & 0.97 \\
\hline & $\mathrm{N} 40 \times 40 \times 4$ & & 0.22 & 1.25 & 1.34 & 1.32 & 1.66 & 1.11 & 0.97 & 0.97 \\
\hline & $\mathrm{N} 80 \times 80 \times 2$ & & 0.82 & 1.28 & 1.22 & 1.22 & 1.14 & - & 1.05 & 1.01 \\
\hline & $\mathrm{N} 80 \times 80 \times 5$ & & 0.33 & 1.37 & 1.51 & 1.49 & 1.80 & 1.16 & 1.12 & 1.08 \\
\hline & $\mathrm{N} 100 \times 50 \times 2$ & & 0.50 & 1.30 & 1.55 & 1.51 & 1.87 & 1.28 & 1.29 & 1.20 \\
\hline & $\mathrm{N} 100 \times 50 \times 4$ & & 0.27 & 1.47 & 1.75 & 1.71 & 2.17 & 1.20 & 1.29 & 1.11 \\
\hline & $\mathrm{N} 120 \times 60 \times 2$ & & 0.67 & 1.25 & 1.19 & 1.19 & 1.40 & 1.22 & 1.11 & 1.08 \\
\hline & $\mathrm{N} 120 \times 60 \times 4$ & & 0.34 & 1.47 & 1.83 & 1.80 & 2.26 & 1.21 & 1.39 & 1.18 \\
\hline & $\mathrm{H} 40 \times 40 \times 2$ & \multirow{2}{*}{ Duplex } & 0.48 & 1.22 & 1.23 & 1.21 & 1.44 & 1.17 & 1.01 & 1.09 \\
\hline & $\mathrm{H} 50 \times 50 \times 1.5$ & & 0.77 & 1.37 & 1.31 & 1.31 & 1.22 & - & 1.10 & 1.12 \\
\hline & $\mathrm{H} 150 \times 150 \times 3$ & HSA & 1.17 & 1.22 & 1.14 & 1.14 & 1.05 & - & 1.07 & 1.04 \\
\hline
\end{tabular}




\begin{tabular}{|c|c|c|c|c|c|c|c|c|c|c|}
\hline & $\mathrm{H} 150 \times 150 \times 6$ & & 0.57 & 1.13 & 1.25 & 1.23 & 1.45 & 1.15 & 1.07 & 1.06 \\
\hline & $\mathrm{H} 140 \times 80 \times 3$ & \multirow{2}{*}{ Duplex } & 0.56 & 1.09 & 1.21 & 1.18 & 1.45 & 1.12 & 1.07 & 1.06 \\
\hline & $\mathrm{H} 160 \times 80 \times 3$ & & 0.65 & 1.01 & 1.09 & 1.07 & 1.32 & 1.17 & 1.05 & 1.06 \\
\hline & $\mathrm{H} 200 \times 110 \times 4$ & HSA & 0.66 & 0.90 & 1.09 & 1.07 & 1.31 & 1.03 & 1.01 & 0.93 \\
\hline \multirow{8}{*}{8} & $100 \times 100 \times 4-B 1$ & \multirow{8}{*}{1.4162} & 0.63 & 1.25 & 1.24 & 1.24 & 1.41 & 1.17 & 1.09 & 1.05 \\
\hline & $100 \times 100 \times 4-B 2$ & & 0.65 & 1.19 & 1.21 & 1.21 & 1.35 & 1.14 & 1.05 & 1.02 \\
\hline & $80 \times 80 \times 4-B 1$ & & 0.52 & 1.14 & 1.19 & 1.17 & 1.39 & 1.12 & 1.00 & 1.05 \\
\hline & $80 \times 80 \times 4-B 2$ & & 0.52 & 1.12 & 1.17 & 1.16 & 1.37 & 1.10 & 0.99 & 1.03 \\
\hline & $60 \times 60 \times 3-B 1$ & & 0.49 & 1.08 & 1.17 & 1.16 & 1.38 & 1.05 & 0.96 & 0.97 \\
\hline & $60 \times 60 \times 3-B 2$ & & 0.50 & 1.11 & 1.20 & 1.19 & 1.42 & 1.08 & 0.99 & 1.00 \\
\hline & $80 \times 40 \times 4-B 1$ & & 0.29 & 1.17 & 1.30 & 1.26 & 1.63 & 1.13 & 0.98 & 1.03 \\
\hline & $80 \times 40 \times 4-B 2$ & & 0.28 & 1.28 & 1.43 & 1.39 & 1.79 & 1.24 & 1.08 & 1.13 \\
\hline \multirow{16}{*}{9} & SHS-50×2-B1 & \multirow{16}{*}{304} & 0.71 & 1.74 & 1.69 & 1.69 & 1.64 & - & 1.33 & 1.24 \\
\hline & SHS-80×3-B3 & & 0.63 & 1.50 & 1.35 & 1.35 & 1.50 & 1.26 & 1.16 & 1.14 \\
\hline & SHS-80×3-B4 & & 0.63 & 1.46 & 1.32 & 1.32 & 1.46 & 1.23 & 1.13 & 1.11 \\
\hline & SHS-80×4-B3 & & 0.48 & 1.29 & 1.42 & 1.40 & 1.66 & 1.24 & 1.15 & 1.15 \\
\hline & SHS-80×4-B4 & & 0.49 & 1.18 & 1.30 & 1.28 & 1.52 & 1.14 & 1.06 & 1.05 \\
\hline & SHS-100×3-B3 & & 0.79 & 1.57 & 1.51 & 1.51 & 1.43 & - & 1.22 & 1.09 \\
\hline & SHS-100×4-B2 & & 0.60 & 1.27 & 1.55 & 1.55 & 1.78 & 1.33 & 1.32 & 1.21 \\
\hline & SHS-100×4-B3 & & 0.60 & 1.24 & 1.52 & 1.52 & 1.74 & 1.30 & 1.29 & 1.18 \\
\hline & RHS- $75 \times 45 \times 2-B 3$ & & 0.64 & 1.39 & 1.46 & 1.46 & 1.71 & 1.32 & 1.30 & 1.20 \\
\hline & RHS- $75 \times 45 \times 2-B 4$ & & 0.63 & 1.15 & 1.39 & 1.39 & 1.64 & 1.25 & 1.23 & 1.14 \\
\hline & RHS- $95 \times 45 \times 2-B 3$ & & 0.65 & 1.06 & 1.31 & 1.28 & 1.57 & 1.19 & 1.19 & 1.07 \\
\hline & RHS- $95 \times 45 \times 2-B 4$ & & 0.63 & 1.02 & 1.26 & 1.23 & 1.51 & 1.12 & 1.14 & 1.02 \\
\hline & RHS $-100 \times 50 \times 2-B 3$ & & 0.75 & 1.36 & 1.34 & 1.34 & 1.33 & - & 1.12 & 1.05 \\
\hline & RHS $-100 \times 50 \times 2-B 4$ & & 0.74 & 1.45 & 1.42 & 1.42 & 1.41 & - & 1.19 & 1.12 \\
\hline & RHS- $120 \times 60 \times 3-B 3$ & & 0.53 & 1.22 & 1.32 & 1.29 & 1.60 & 1.23 & 1.15 & 1.18 \\
\hline & RHS- $120 \times 60 \times 3-B 4$ & & 0.53 & 1.26 & 1.35 & 1.33 & 1.64 & 1.26 & 1.18 & 1.21 \\
\hline \multirow{10}{*}{10} & $50 \times 30 \times 2.5 \mathrm{~L} 900$ & \multirow{10}{*}{1.4162} & 0.30 & 1.24 & 1.38 & 1.35 & 1.71 & 1.20 & 1.04 & 1.11 \\
\hline & $30 \times 50 \times 2.5 \mathrm{~L} 900$ & & 0.45 & 1.11 & 1.20 & 1.19 & 1.41 & 1.08 & 0.96 & 1.00 \\
\hline & $50 \times 50 \times 1.5 \mathrm{~L} 900$ & & 0.81 & 1.35 & 1.29 & 1.29 & 1.19 & - & 1.09 & 1.04 \\
\hline & $50 \times 50 \times 2.5 \mathrm{~L} 900$ & & 0.50 & 1.21 & 1.35 & 1.33 & 1.58 & 1.17 & 1.11 & 1.09 \\
\hline & $70 \times 50 \times 2.5 \mathrm{~L} 1100$ & & 0.51 & 1.13 & 1.29 & 1.27 & 1.54 & 1.11 & 1.08 & 1.04 \\
\hline & $50 \times 70 \times 2.5 \mathrm{~L} 1100$ & & 0.68 & 1.42 & 1.38 & 1.38 & 1.34 & - & 1.08 & 1.05 \\
\hline & $100 \times 50 \times 2.5 \mathrm{~L} 1500$ & & 0.54 & 1.10 & 1.25 & 1.23 & 1.52 & 1.11 & 1.09 & 1.06 \\
\hline & $50 \times 100 \times 2.5 \mathrm{~L} 1500$ & & 0.94 & 1.42 & 1.30 & 1.30 & 1.04 & - & 1.04 & 0.99 \\
\hline & $150 \times 50 \times 2.5 \mathrm{~L} 1500$ & & 0.70 & 1.33 & 1.06 & 1.04 & 1.35 & - & 1.09 & 1.09 \\
\hline & $50 \times 150 \times 2.5 \mathrm{~L} 1500$ & & 1.30 & 1.42 & 1.26 & 1.26 & 0.95 & - & 0.97 & 0.97 \\
\hline \multirow{4}{*}{11} & RHS $120 \times 80 \times 3-4 \mathrm{~PB}$ & & 0.56 & 1.01 & 1.10 & 1.08 & 1.30 & 1.04 & 0.96 & 0.96 \\
\hline & RHS60 $040 \times 3-4 \mathrm{~PB}$ & 1.4003 & 0.28 & 1.04 & 1.18 & 1.15 & 1.43 & 1.01 & 0.86 & 0.99 \\
\hline & SHS $80 \times 80 \times 3-4 \mathrm{~PB}$ & & 0.56 & 1.02 & 1.10 & 1.08 & 1.27 & 1.05 & 0.94 & 0.99 \\
\hline & SHS60×60×3-4PB & 1.4509 & 0.43 & 1.05 & 1.11 & 1.10 & 1.30 & 1.05 & 0.88 & 1.02 \\
\hline
\end{tabular}




\begin{tabular}{|c|c|c|c|c|c|c|c|c|c|c|}
\hline & RHS $120 \times 80 \times 3-3 P B$ & \multirow{3}{*}{1.4003} & 0.57 & 1.07 & 1.17 & 1.15 & 1.38 & 1.11 & 1.02 & 1.02 \\
\hline & RHS $60 \times 40 \times 3-3 P B$ & & 0.29 & 1.15 & 1.30 & 1.27 & 1.58 & 1.12 & 0.96 & 1.10 \\
\hline & SHS $80 \times 80 \times 3-3 \mathrm{~PB}$ & & 0.56 & 1.02 & 1.10 & 1.08 & 1.27 & 1.05 & 0.94 & 0.99 \\
\hline & SHS $60 \times 60 \times 3-3 \mathrm{~PB}$ & 1.4509 & 0.44 & 1.13 & 1.20 & 1.18 & 1.40 & 1.13 & 0.94 & 1.10 \\
\hline \multirow{9}{*}{12} & $60 \times 60 \times 2-3 P$ & \multirow{9}{*}{1.4003} & 0.64 & 1.04 & 0.94 & 0.94 & 1.03 & 0.88 & 0.81 & 0.80 \\
\hline & $80 \times 40 \times 2-3 P$ & & 0.77 & 1.23 & 1.16 & 1.16 & 1.04 & - & 0.91 & 0.88 \\
\hline & $60 \times 60 \times 2-4 P$ & & 0.65 & 1.16 & 1.07 & 1.07 & 1.15 & 1.00 & 0.91 & 0.90 \\
\hline & $70 \times 50 \times 2-4 \mathrm{P}$ & & 0.57 & 0.98 & 1.05 & 1.05 & 1.35 & 1.03 & 1.00 & 0.98 \\
\hline & $70 \times 50 \times 2-4 P$ & & 0.72 & 1.21 & 1.16 & 1.16 & 1.10 & - & 0.93 & 0.91 \\
\hline & $80 \times 40 \times 2-4 \mathrm{P}$ & & 0.47 & 0.97 & 1.06 & 1.06 & 1.42 & 0.96 & 0.96 & 0.92 \\
\hline & $80 \times 40 \times 2-4 \mathrm{P}$ & & 0.77 & 1.19 & 1.11 & 1.11 & 1.00 & - & 0.87 & 0.85 \\
\hline & $100 \times 40 \times 2-4 \mathrm{P}$ & & 0.50 & 0.78 & 0.84 & 0.84 & 1.13 & 0.79 & 079 & 0.77 \\
\hline & $100 \times 40 \times 2-4 \mathrm{P}$ & & 0.94 & 1.31 & 1.20 & 1.20 & 0.93 & - & 0.94 & 0.90 \\
\hline \multirow{5}{*}{13} & SHS $50 \times 50 \times 3$ & \multirow{5}{*}{$\begin{array}{l}1.4301 \\
1.4307\end{array}$} & 0.42 & 1.25 & 1.43 & 1.41 & 1.68 & 1.14 & 1.11 & 1.06 \\
\hline & SHS60×60×3 & & 0.47 & 1.22 & 1.38 & 1.36 & 1.61 & 1.16 & 1.10 & 1.07 \\
\hline & SHS $100 \times 100 \times 3$ & & 0.75 & 1.47 & 1.42 & 1.42 & 1.35 & - & 1.14 & 1.07 \\
\hline & RHS $60 \times 40 \times 3-\mathrm{MA}$ & & 0.36 & 1.27 & 1.52 & 1.49 & 1.84 & 1.06 & 1.16 & 1.04 \\
\hline & RHS60×40×3-MI & & 0.49 & 1.24 & 1.43 & 1.42 & 1.66 & 1.20 & 1.15 & 1.10 \\
\hline \multirow{5}{*}{14} & SHS $100 \times 100 \times 5$ & 1.4301 & 0.46 & 1.30 & 1.49 & 1.46 & 1.73 & 1.23 & 1.17 & 1.12 \\
\hline & SHS $120 \times 120 \times 5$ & 1.4571 & 0.50 & 1.19 & 1.42 & 1.40 & 1.65 & 1.17 & 1.14 & 1.06 \\
\hline & RHS $150 \times 100 \times 6$ & 1.4307 & 0.36 & 1.16 & 1.60 & 1.57 & 1.93 & 1.01 & 1.19 & 0.94 \\
\hline & RHS $150 \times 100 \times 8$ & 1.4404 & 0.36 & 1.07 & 1.44 & 1.42 & 1.68 & 0.94 & 1.05 & 0.87 \\
\hline & SHS $150 \times 150 \times 8$ & 1.4162 & 0.45 & 1.09 & 1.43 & 1.41 & 1.69 & 1.02 & 1.11 & 0.94 \\
\hline \multirow{2}{*}{15} & SHS $40 \times 40 \times 2$ & \multirow{2}{*}{1.4509} & 0.44 & 1.08 & 1.23 & 1.21 & 1.44 & 1.05 & 0.96 & 1.03 \\
\hline & SHS $50 \times 50 \times 2$ & & 0.57 & 0.98 & 1.11 & 1.10 & 1.29 & 1.02 & 0.95 & 0.93 \\
\hline \multirow{2}{*}{16} & SHS60×60×3 & \multirow{2}{*}{1.4003} & 0.44 & 1.06 & 1.17 & 1.16 & 1.38 & 1.04 & 0.92 & 1.02 \\
\hline & SHS $100 \times 40 \times 2$ & & 1.00 & 1.47 & 1.33 & 1.33 & 1.02 & - & 1.07 & 1.03 \\
\hline \multirow{6}{*}{$\begin{array}{l}\text { This } \\
\text { paper }\end{array}$} & SHS70×3-1900a & \multirow{4}{*}{304} & 0.50 & 1.19 & 1.33 & 1.31 & 1.55 & 1.16 & 1.09 & 1.07 \\
\hline & SHS70×3-1900b & & 0.50 & 1.22 & 1.36 & 1.34 & 1.58 & 1.19 & 1.11 & 1.09 \\
\hline & SHS100×3-1900a & & 0.68 & 1.42 & 1.39 & 1.39 & 1.37 & 1.24 & 1.10 & 1.08 \\
\hline & SHS100×3-1900b & & 0.68 & 1.42 & 1.39 & 1.39 & 1.37 & - & 1.10 & 1.08 \\
\hline & \multicolumn{2}{|l|}{ AVG. } & & 1.22 & 1.31 & 1.30 & 1.48 & 1.12 & 1.07 & 1.04 \\
\hline & \multicolumn{2}{|l|}{ COV. } & & 0.16 & 0.17 & 0.17 & 0.26 & 0.11 & 0.11 & 0.10 \\
\hline
\end{tabular}

Note: $\uparrow$ Other two continuous beam tests are not shown in this table, as the bending capacities of the specimens can not be determined directly by the load force. - Section slenderness is higher than 0.68 , which is beyond the applicable limit of CSM method. 
Table 9 Comparisons of test results and predictions of the current design methods and the proposed design method for circular hollow sections.

\begin{tabular}{|c|c|c|c|c|c|c|c|c|c|}
\hline Ref. & Specimens & Grade & $\lambda$ & $\frac{M_{t}}{M_{\mathrm{en}}}$ & $\frac{M_{t}}{M_{\text {asce }}}$ & $\frac{M_{t}}{M_{\mathrm{au}}}$ & $\frac{M_{t}}{M_{\mathrm{cn}}}$ & $\frac{M_{t}}{M_{\mathrm{csm}}}$ & $\frac{M_{t}}{M_{\mathrm{p}}}$ \\
\hline 2 & C1B1 & $304 \mathrm{~L}$ & 0.24 & 1.15 & 1.50 & 1.15 & 1.50 & 1.15 & 1.10 \\
\hline \multirow{8}{*}{17} & TB01 & \multirow{4}{*}{304} & 0.37 & 1.24 & 1.56 & 1.24 & 1.24 & 1.31 & 1.16 \\
\hline & TB02 & & 0.47 & 1.17 & 1.74 & 1.17 & - & 1.29 & 1.28 \\
\hline & TB03 & & 0.47 & 1.06 & 1.48 & 1.06 & - & 1.17 & 1.17 \\
\hline & TB04 & & 0.41 & 1.25 & 1.66 & 1.25 & - & 1.34 & 1.24 \\
\hline & TB05 & \multirow{4}{*}{2205} & 0.33 & 1.32 & 1.44 & 1.32 & 1.32 & 1.37 & 1.15 \\
\hline & TB06 & & 0.33 & 1.30 & 1.44 & 1.30 & 1.30 & 1.35 & 1.14 \\
\hline & TB07 & & 0.42 & 0.96 & 1.23 & 0.96 & - & 1.04 & 0.98 \\
\hline & TB08 & & 0.36 & 1.33 & 1.59 & 1.33 & - & 1.40 & 1.23 \\
\hline \multirow{3}{*}{18} & TB09 & 1.4541 & 0.20 & 1.21 & 1.59 & 1.21 & 1.59 & 1.14 & 1.07 \\
\hline & TB10 & \multirow{2}{*}{1.4435} & 0.27 & 1.37 & 1.37 & 1.37 & 1.37 & 1.14 & 1.06 \\
\hline & TB11 & & 0.30 & 1.25 & 1.25 & 1.25 & 1.25 & 1.28 & 1.04 \\
\hline \multirow{6}{*}{$\begin{array}{l}\text { This } \\
\text { paper }\end{array}$} & CHS89×3-1900a & \multirow{4}{*}{304} & 0.21 & 1.21 & 1.59 & 1.21 & 1.59 & 1.14 & 1.09 \\
\hline & CHS89×3-1900b & & 0.21 & 1.15 & 1.51 & 1.15 & 1.51 & 1.08 & 1.04 \\
\hline & CHS127×3-1900a & & 0.23 & 1.07 & 1.40 & 1.07 & 1.40 & 1.07 & 1.02 \\
\hline & CHS127×3-1900b & & 0.23 & 1.07 & 1.39 & 1.07 & 1.39 & 1.06 & 1.01 \\
\hline & \multicolumn{2}{|l|}{ AVG. } & & 1.19 & 1.48 & 1.19 & 1.41 & 1.21 & 1.11 \\
\hline & \multicolumn{2}{|l|}{ COV. } & & 0.11 & 0.14 & 0.11 & 0.13 & 0.12 & 0.09 \\
\hline
\end{tabular}

Note: - $D / t$ ratios of these test specimens are beyond the limit in Chinese code. 